\title{
The Training of Short Distance Sprint Performance in Football Code Athletes: A Systematic Review and Meta-Analysis
}

\author{
Ben Nicholson ${ }^{1,2,3} \cdot$ Alex Dinsdale $^{1} \cdot$ Ben Jones ${ }^{1,3,4,5,6} \cdot$ Kevin Till $^{1,3}$
}

Published online: 27 November 2020

(c) The Author(s) 2020

\begin{abstract}
Background Short-sprint $(\leq 20 \mathrm{~m})$ performance is an important quality for success in the football codes. Therefore, developing an evidence base for understanding training methods to enhance short-sprint performance is key for practitioners. However, current systematic reviews are limited by (1) a lack of focus on football code athletes, (2) a lack of consideration of all training modalities and (3) a failure to account for the normal training practices undertaken by intervention groups within their analysis. Therefore, this review aimed to (1) conduct a systematic review of the scientific literature evaluating training interventions upon short-sprint performance within football code athletes, (2) undertake a meta-analysis to assess the magnitude of change of sport-sprint performance following training interventions and (3) identify how moderator variables affect the training response.

Methods A systematic search of electronic databases was conducted. A random-effects meta-analysis was performed to establish standardised mean difference with $95 \%$ confidence intervals. This identified the magnitude and direction of the individual training effects of intervention subgroups (primary, secondary, combined-specific, tertiary and combined training methods) on short-sprint performance while considering moderator variables (i.e., football code, sex, age, playing standard, phase of season).

Results 121 studies met the inclusion criteria, totalling 3419 athletes. Significant improvements (small-large) were found between pre- and post-training in short-sprint performance for the combined, secondary, tertiary and combined-specific training methods. No significant effect was found for primary or sport only training. No individual mode was found to be the most effective. Between-subgroup analysis identified that football code, age, playing standard and phase of season all moderated the overall magnitude of training effects.

Conclusions This review provides the largest systematic review and meta-analysis of short-sprint performance development methods and the only one to assess football code athletes exclusively. Practitioners can apply combined, secondary and tertiary training methods to improve short-sprint performance within football code athletes. The application of sport only and primary methods does not appear to improve short-sprint performance. Regardless of the population characteristics, short-sprint performance can be enhanced by increasing either or both the magnitude and the orientation of force an athlete can generate in the sprinting action.
\end{abstract}

Trial Registration OSF registration https://osf.io/kshqn/.

Electronic supplementary material The online version of this article (https://doi.org/10.1007/s40279-020-01372-y) contains supplementary material, which is available to authorized users.

Ben Nicholson

B.t.nicholson@leedsbeckett.ac.uk

Extended author information available on the last page of the article 


\section{Key Points}

Short-sprint performance (0-5, 0-10 and 0-20 m) of football code athletes can be enhanced through secondary (i.e., resisted or assisted sprinting), tertiary (i.e., strength, power and plyometrics) and combined (i.e., primary [i.e., sprinting, running drills] or secondary and tertiary) training methods. Combined specific training methods (i.e., primary and secondary methods) improved short-sprint performance $(0-5$ and $0-10 \mathrm{~m})$. However, the sport only and primary methods alone do not appear to enhance short-sprint performance. No individual mode was found to be the most effective.

Independent of the population characteristics, findings suggest that practitioners should develop either or both the magnitude and the orientation of forces an athlete can generate and express in the sprinting action to improve short-sprint performance.

Research has mainly been undertaken within male soccer athletes including some form of tertiary training methods (e.g., strength, power and plyometrics training).

\section{Introduction}

The development of short-distance sprint (short-sprint) performance (i.e., 5-20 m) is a vital component of athletic performance within the football codes [1]. A football code athlete's ability to produce high levels of linear speed (at various short distances) has been shown to be a factor differentiating within playing standards [2-4] and age categories $[2,4,5]$, as well as being associated with success in key attacking and defensive performance indicators across football codes (i.e., rugby league [6, 7], Australian rules football [8], rugby union $[9,10]$, rugby sevens [11] and soccer [12]). This body of evidence emphasises the importance of short-sprint performance for football performance and player development. Due to the high frequency of short-sprints with incomplete rest, present in the football codes, repeat sprint ability (RSA) is also considered an important factor for an athlete's sprinting capabilities [1,13]. Previous research has reported small-large relationships $(r=0.44-0.86)$ between short-sprint performance $(0-5 \mathrm{~m}, 0-10 \mathrm{~m}, 0-20 \mathrm{~m})$ and RSA $[14,15]$. As such maximum short-sprint performance may also positively influence RSA. However, the physical adaptations required to develop these qualities are distinctly separate and thus will not be considered within this review [13]. Understanding the most effective, evidence-based methods for developing sprint performance is a challenge for all practitioners involved in the football codes, due to the concurrent developmental need of multiple physical qualities (e.g., speed, strength, power and endurance) alongside technical and tactical skills $[1,2,16]$. Hence, concurrent or conflicting training systems exist. This differs from track sprinters and non-athletic populations and needs to be considered when prescribing training for football code athletes.

Although definitions vary, sprint performance is typically split into two components: acceleration and maximal sprinting velocity phases [17-26]. Despite being sequential, moderate to large correlations have been identified between acceleration and maximum sprinting velocity in football code athletes $(r=0.56-0.87)$. This suggests that even though these phases are related, separate physical qualities and mechanical parameters determine sprint performance [21, 27-30]. Mechanically, athletes exhibit relatively lower stride frequencies (i.e., longer foot contacts and shorter flight times), shorter stride lengths and an increased forward trunk lean when accelerating [18, 31-33]. Notably, football code athletes typically achieve maximal sprint velocity $\left(V_{\max }\right)$ at shorter distances (15-40 m vs. 40-60 m respectively) with lower maximal velocities $\left(\sim 7-10 \mathrm{vs} .>12 \mathrm{~m} \cdot \mathrm{s}^{-1}\right)$ compared to well-trained, male elite sprinters [18, 21, 30, 34-36]. Furthermore, football code athletes attain a greater percentage of maximal velocity at shorter distances (e.g., $90 \%$ at $13.7 \mathrm{~m}$ in American Football [30], 96\% at $21 \mathrm{~m}$ in rugby [18]). As a result practitioners and researchers typically use linear shortsprint performance outcomes (i.e., time to completion or peak velocity achieved) as a proxy measure for acceleration performance (e.g., 0-5 m, 0-10 m, 0-20 m) across its sequential phases $[16,37,38]$. Therefore, as a population, football code athletes exhibit different physical and technical approaches to sprinting [34], when compared to well-trained sprinters. This highlights the need for specifically targeted sprint-based research within the football codes.

Research has previously reported that short-sprint performance is a trainable quality in football code athletes (i.e., soccer, $20 \mathrm{~m}$ performance) [39]. However, the training response in short-sprint performance is highly variable [40-42]. Previous research has shown that training responses are modespecific with distance specific performance changes (e.g., 0-10 $\mathrm{m}$ and $0-20 \mathrm{~m}$ ) associated with phase-specific adaptations [43]. Training modes have been classified based on task specificity into the following subgroups; primary (e.g., sprint technique, sprinting), secondary (e.g., resisted or assisted sprinting) or tertiary (e.g., non-specific methods including resistance training and plyometrics) [44]. Despite the importance of short-sprint performance, it is currently unclear both individually and across football codes what method is best to enhance performance. Hence, developing short-sprint performance is a collective problem across codes. Conducting a cross-football codes systematic review would allow a more comprehensive overview of the available literature than a single sport, while also comparing best methods of developing 
short-sprint performance. However, the magnitude and direction of the training effect can be affected by "moderator" variables presenting fluctuating changes based on population characteristics such as the sport [45], age [46] and sex [47] of the athlete, and training phase (e.g., pre-season [48]). Therefore, it is important to identify the moderator variables and evaluate the extent that they may affect the resultant training effect when training short-sprint speed [49].

Despite the plethora of research evaluating the effectiveness of short-sprint training interventions alongside several systematic reviews and meta-analyses, several limitations exist in the current literature. These are (1) no review focuses upon only football code athletes, instead including sprinters and non-athletes [39, 43, 46, 48, 50-57]; (2) no study examines all training modalities across football code athletes on short-sprint performance [39, 43, 46, 48, 50-57]; and (3) previous systematic reviews and meta-analyses [39, $43,48]$ fail to account for the normal training practices undertaken by training intervention groups (e.g., training categorised as a resisted sled intervention also including 2 strength sessions per week) within their reviews and analysis. These limitations heavily influence the interpretation and knowledge associated with sprint training interventions for applying effective evidence-based practices within football code athletes. Therefore, the aims of this review were to (1) systematically review the scientific literature evaluating the training interventions upon short-sprint performance (0-5 m, 0-10 m, 0-20 m) within football code athletes, (2) undertake a meta-analysis to assess the magnitude of change of short-sprint performance following training interventions; and (3) identify how moderator variables (i.e., football code, sex, playing standard, age and phase of season) affect the training response.

\section{Methods}

\subsection{Design and Search Strategy}

A systematic review and meta-analysis were conducted in accordance with the Preferred Reporting Items for Systematic Reviews and Meta-Analyses (PRISMA) statement and followed the Prospero guidelines [58]. Due to the nature of the project, the review protocol was prospectively registered on the database for open science framework (OSF) https:// osf.io/kshqn/. A systematic search of electronic databases (PubMed, The Cochrane Library, MEDLINE, SPORTDiscus and CINAHL, via EBSCOhost) was conducted to identify original research articles published from the earliest available records up to and including 14/10/2019. Boolean search phrases were used to include search terms relevant to football code athletes (population), the training intervention (dependent variable) and the short-sprint performance outcomes (independent variable). Relevant keywords for each search term were determined through pilot searching (screening of titles/abstracts/keywords/full texts of previously known articles). Keywords were combined withinterms using the 'OR' operator, and the final search phrase was constructed by combining the three search terms using the 'AND' operator (Table 1).

Additional records were taken from the bibliographies of eligible studies and previous reviews which were explored using Google Scholar. Attempts were made to contact the authors of the selected articles to request any missing relevant information. No age or sex restrictions were imposed during the search stage.

\subsection{Study Selection}

Duplicate records were identified and removed before the remaining records were screened against the predefined inclusion-exclusion criteria (Table 2). Studies were screened independently by two researchers (BN, AD). The screening of the journal articles was completed over two phases. Studies were initially excluded based on the content of the titles and abstracts followed by a full-text review. In the event of disagreement in the reviewer's decision, reviewers met to come to an agreed decision on the paper. Disparities in study selection were resolved by a 3rd member (KT).

\subsection{Data Extraction}

One author (BN) extracted the data using a specifically designed standardised excel spreadsheet. General study information (i.e., author, year), subject characteristics (i.e., sample size, sex, age, body mass, height, sport, training status, performance level), training intervention characteristics (i.e., training methods, control group information, number of sessions per week, duration of training intervention, total amount of training sessions, training intensity, training volume, testing distances, testing equipment, training surface, other training, reported training-related injuries) and primary outcome measures (i.e., pre- and post-training intervention means and standard deviations) were extracted. All studies that included the time or velocity achieved from the initial start position $(0 \mathrm{~m})$ to $\leq 5 \mathrm{~m}, 0 \mathrm{~m}$ to between $>5 \mathrm{~m}$ to $\leq 10 \mathrm{~m}$ and $0 \mathrm{~m}$ to between $>10 \mathrm{~m}$ to $\leq 20 \mathrm{~m}$ were categorised into the $0-5 \mathrm{~m}, 0-10 \mathrm{~m}$ and $0-20 \mathrm{~m}$ subgroups respectively. These outcomes aimed to identify training mode specific short-sprint performance changes, whilst representing the typical short-sprint distances performed by football code athletes and those commonly measured by researchers/practitioners.

Descriptive information relating to the training activities performed in the studies was used to categorise each intervention into the training mode subgroups outlined in Table 3. 
If the pre- and post-outcome measure data was not available from the tables or the result section, the data was requested from the author(s). If the authors did not have access to their data, data on outcome measures were extracted from figures using WebPlotDigitizer version 4.1 software (2018) (Version 4.1, WebPlotDigitizer, USA). Means and SD/SEM were measured manually at the pixel level to the scale provided in the studies figures.

\subsection{Study Quality Assessment}

The study quality assessment of the included studies was assessed using the McMaster [59] scale, which is relevant for sport science research. This scale expands upon the scale created by Brughelli [60] designed to evaluate research conducted in athletic-based training environments from a combination of items from the Cochrane, Delphi and PEDRO. The methodological scale assesses the study in the following 10 domains: inclusion criteria stated, subject assignment, intervention description, control groups, dependent variables definition, assessment methods, study duration, statistics, results section and conclusions. A score of $0=$ clearly no; $1=$ maybe; and $2=$ clearly yes were assigned based on a total study quality assessed from 20 .

\subsection{Data Analysis and Meta-analyses}

Data extracted from the systematic search were included in the meta-analyses. Improvements in sprint performance are typically identified by a reduction in time taken to cover a given distance or an increase in peak velocity achieved for a given time point and or distance $[37,61]$. Therefore, preand post-time changes were reversed before conducting the analysis so that both time and velocity changes represented the same direction. Thus, identifying a reduction in time or an increase in velocity for a given distance as a positive change.

A random-effects meta-analyses was performed by using Comprehensive Meta-Analysis Version 3.0 software (version 3, Biostat, Englewood, NJ, USA) to assess the magnitude of the outcome across the relevant primary studies and to explore the effect of moderator variables on the variation
Table 1 Database literature search strategy

\begin{tabular}{ll}
\hline Search term & Keywords \\
\hline 1. Sports population & "soccer" OR "football" OR "rugby" OR "futsal" \\
& (NOT/- "sprinters" OR "swimming" OR "cycling" OR "Paralympic") \\
2. Training intervention & "sprinting" OR "sprint" OR "training" OR "speed" OR "resisted" \\
& OR "assisted" OR "resistance" OR "power" OR "strength" OR \\
& "plyometric" OR "weightlifting" OR "strongman" OR "technique" \\
& OR "weight" OR "sled" OR "intervention" OR "sprint mechanics" \\
3. Outcome measures & "sprint performance" OR "acceleration" OR "velocity" \\
Search phrase: & 1 AND 2 AND 3 \\
\hline
\end{tabular}

Table 2 Inclusion/exclusion criteria (title/abstract screening and full screening)

\begin{tabular}{ll}
\hline Criteria & Inclusion \\
\hline 1 & $\begin{array}{l}\text { Studies with human subjects and has a pre-and-post-outcome } \\
\text { measure/s identifying sprint performance } \leq 20 \mathrm{~m}\end{array}$ \\
2 & Training intervention study with the training programme clearly \\
& outlined, designed to produce chronic adaptions (not acute). \\
& Interventions would include: specific sprint training (resisted, \\
& assisted, un-resisted sprinting, sprint mechanics and tech- \\
& nique training), non-specific sprint training (strength, power, \\
& plyometric training, and non-traditional methods) and combined \\
& sprint training (combined specific, combined non-specific and \\
& combined mixed methods \\
& Original research article \\
& Population-Football codes athletes. Football athletes would \\
& be defined as those who are competing within a football \\
& code. Football codes for inclusion: soccer, American football, \\
& Canadian football, Australian rules football, rugby union, rugby \\
& league, rugby sevens, Gaelic football, futsal \\
& Healthy, able-bodied, non-injured athletes
\end{tabular}

Exclusion

Studies with non-human subjects and/or no pre-and-post-outcome measure/s identifying sprint performance $>20 \mathrm{~m}$

Inappropriate study design — not an intervention study or an acute/ post-activation study

Reviews, surveys, opinion pieces, books, periodicals and editorials

Non-football code sports (e.g., solo, racquet/bat, or combat sports), match officials, or non-athletic populations

Special populations (e.g., clinical, patients), athletes with a physical or mental disability, and athletes considered to be injured or returning from injury 
among study outcomes [62]. Outcome measures were converted into the standardised mean difference (SMD) with 95\% confidence intervals (CI) and were used as the summary statistic. The SMD represents the size of the effect of the intervention relative to the variability observed in that intervention. Overall summary estimates were calculated for each of the training type subgroups: primary, secondary, combined specific, tertiary, combined methods and sport only training (Table 3). An inverse-variance random-effects model was used for the meta-analyses because it allocated a proportionate weight to trials based on the size of their individual standard errors and facilitates analysis while controlling for heterogeneity across studies [63]. The inputted data included sample sizes, outcome measures with their respective standard deviations and a correlation coefficient for within-subject measurements. These correlation coefficients (0-5 $\mathrm{m} r=0.69,0-10 \mathrm{~m} r=0.72$ and $0-20 \mathrm{~m} r=0.76$ ) were estimated from prior field testing and other published studies [64-66].

The SMD values were interpreted as $<0.20$ as trivial, $0.20-0.39$ as small, $0.40-0.80$ as moderate and $>0.80$ as large [67]. A positive SMD indicates that the training intervention was associated with an improvement in shortsprint performance while a negative SMD indicates that the training intervention was associated with a decrease in the respective performance outcome. Accompanying $p$ values tested the null hypothesis that there was no statistically significant change in short-sprint performance regardless of the training method. Statistical significance was considered for $p<0.05$. Heterogeneity between trials was assessed using the $I^{2}$ statistic, moderate (>50\%) to high values (>75\%) were used to indicate for potential heterogeneity sources (Higgins and Thompson 2002) [68]. The $I^{2}$ statistic was supported by reporting the Tau-squared statistic and the Chisquared statistic. Sensitivity analyses were used for each subgroup by repeating the analyses with each study omitted in turn; this would examine whether any conclusions were dependent on a single study.

Subgroup analyses were performed to evaluate the potential moderator variables which were determined a priori: sex (male vs female), football code, playing standard (elite vs. sub-elite; [from Swann et al. (2016), the highest reported standard of performance [69]]), age category (senior [mean age $\geq 18$ years] vs youth [mean age $<18$ years]) and training phase (pre-season vs in-season vs off-season).

\subsection{Evaluation of Small Study Effects}

Small study effects were evaluated through visual interpretation of funnel plots of SMD versus standard errors and by quantifying Egger's linear regression intercept [70] to evaluate potential bias. A statistically significant Egger statistic ( $p$ value $<0.05$ ) indicated the presence of a small study effect.

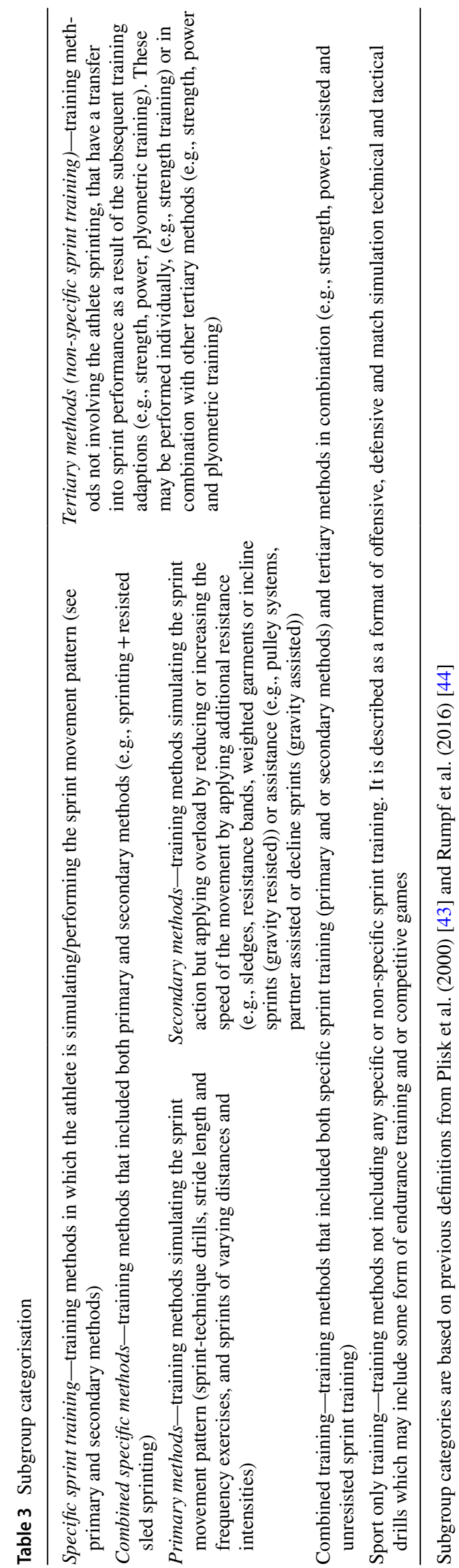




\section{Results}

\subsection{Overview}

Following the removal of duplicates, a total of 1776 studies were found. The study selection inclusion criteria identified 121 studies [40-42, 64-66, 71-181] (Fig. 1). The 121 studies resulted in a total of 220 intervention groups and 64 sport only groups. Training groups were subgrouped into six training classifications (sport only $n=64$, combined methods $n=76$, combined specific methods $n=3$, primary methods $n=11$ [66, 79, 89, 106, 134, 135, 155, 177], secondary methods $n=6[77,79,87,89,173]$ and tertiary methods $n=124$ ) to differentiate between findings for distinct shortsprint performance outcomes (Table 3).

Electronic Supplementary Material Table S1 (non-specific/tertiary, $n=124$ ), Table S2 (combined, $n=76$ ) and Table S3 (specific, $n=20$ ) present the individual training groups study descriptives, training intervention and shortsprint outcomes for the included studies. The 121 studies [40-42, 64-66, 71-181] represented a total sample of 3419 football code athletes with a mean sample size of $12.0 \pm 5.3$ participants per training group. One hundred and ten studies were conducted in males, ten in females $[97,113,127,128$, $139,140,147,151,173,181]$ and one in mixed populations [106]. The mean age of studies ranged from 10.1 to 26.8 years. The athlete populations ranged from sub-elite to elite [69]. Collectively, the training intervention durations ranged from 2 to 26 weeks ( $7.6 \pm 3.6)$, with the intervention training frequency ranging between 1 and 4 sessions per week $(2.1 \pm 0.6)$ over 6-52 individual sessions.

Studies were conducted in soccer $(n=96)$, rugby league $(n=5)[71,72,84,93,104]$, rugby union $(n=4)[103,129$, $175,176]$, futsal $(n=3)[113,159,171]$ rugby sevens $(n=2)$ [75, 182], Australian football $(n=1)$ [162] and mixed football codes $(n=10)$ [40, 42, 64, 105, 114-116, 141, 153, 155]. No studies using Gaelic football or American football players satisfied the inclusion criteria. Studies were conducted in pre-season $(n=38)$, in-season $(n=64)$, offseason $(n=3)$ and across pre-season and in-season $(n=2)$. Fourteen studies did not report the phase of the season. Short-sprint assessment distances ranged from 4.6 to $20 \mathrm{~m}$; $0-5 \mathrm{~m}(n=43), 0-10 \mathrm{~m}(n=85)$ and $0-20 \mathrm{~m}(n=85)$. Timing devices included electronic timing gate systems $(n=98)$, stopwatches $(n=6)$, velocimeters $(n=4)$, radar measurement devices $(n=3)$, high-speed video cameras $(n=3), 1080$ sprint devices $(n=2)$, a laser measurement device $(n=1)$, a kinematic measurement system $(n=1)$ and a mobile application (mysprint; $n=1$ ). One study failed to report the sprint performance measuring device.

Sport only training groups were generally described as some format of offensive or defensive match simulation and technical and tactical drills 2-6 days per week, 2-11 sessions per week lasting between 30 and 120 min per session as well as some form of endurance training and 1-3 competitive or friendly games/week. There were various methods of endurance training described such as simulated games performed in small-, medium- or large-sided games formats (3 vs 3 to 11 vs 11$)$, low-intensity aerobic conditioning, high-intensity interval training and recreational or cardiovascular activities (basketball, biking, running, aerobics, etc.). Sport only training was conducted in both pre-season and in-season periods over a duration of 6-16 weeks.

Specific sprint training groups performed sprinting, resisted and assisted sprinting and technical sprint drills, completed as individual modalities and or/in combination (e.g., complex and contrast sets). The training was performed 1-3 days per week, with intervention periods lasting from 4 to 12 weeks (6-16 sessions). The primary sprint training methods included single set interventions ranging from 8 to 15 repetitions of short distance $(20 \mathrm{~m})$ sprints (160-300 m session totals) or multiple set methods, ranging from $2-5$ sets of 2-8 repetitions/set of medium-long distance (25-55 m) sprints (240-680 m session totals). Two studies $[66,106]$ performed submaximal sprint efforts $(90 \%$ of best $20 \mathrm{~m}$ time), involving 25-30 repetitions of short distance (20 m) sprints (400-600 m session totals). Resisted sprinting was performed as either a single set of 5-10 repetitions of short-sprints (18.3-20 m; 100-200 m session total) or multiple set methods, ranging from 2 to 7 sets of 4 repetitions/ set of short-medium distance $(5-30 \mathrm{~m})$ resisted sled sprints (130-455 m session total). Resisted sprint loads ranged from light-very heavy loads [52]. Loads were prescribed based on percentage body mass (i.e., $10-80 \% \mathrm{BM}$ ) or reduction in $V_{\max }$ corresponding with the additional resistance applied (i.e., $10-50 \%$ reduction in $V_{\max }$ ). One study used partner applied resistance (intensity not specified) for resisted sprints. One study investigated assisted training methods, implementing 1 set of 10 repetitions/set of short-sprints over $18.3 \mathrm{~m}$ with a bungee cord assistive load of 14.7\% BM (183 m session total; [173]).

Non-specific/tertiary sprint training groups consisted of strength, power and/or plyometrics training performed as individual modalities and or/in combination (e.g., complex and contrast sets). The training was performed $1-5$ days per week, with intervention periods lasting from 3 to 16 weeks (6-36 sessions). Lower body strength training (e.g., squat, hip hinge and calf variations) ranged from moderatesupramaximal loads (55-110\% 1RM) moderate-high volume training (e.g., 2-6 sets 2-6 repetitions and/ or 2-6 sets of $8-16$ repetitions). Power training consisted of ballistic exercises (e.g., squat jump, power clean and snatch) at light to moderate loads (30-75\% 1RM) and/or velocity-based training using loads corresponding to the mass at which optimal 
Fig. 1 Flow diagram of the process of study selection

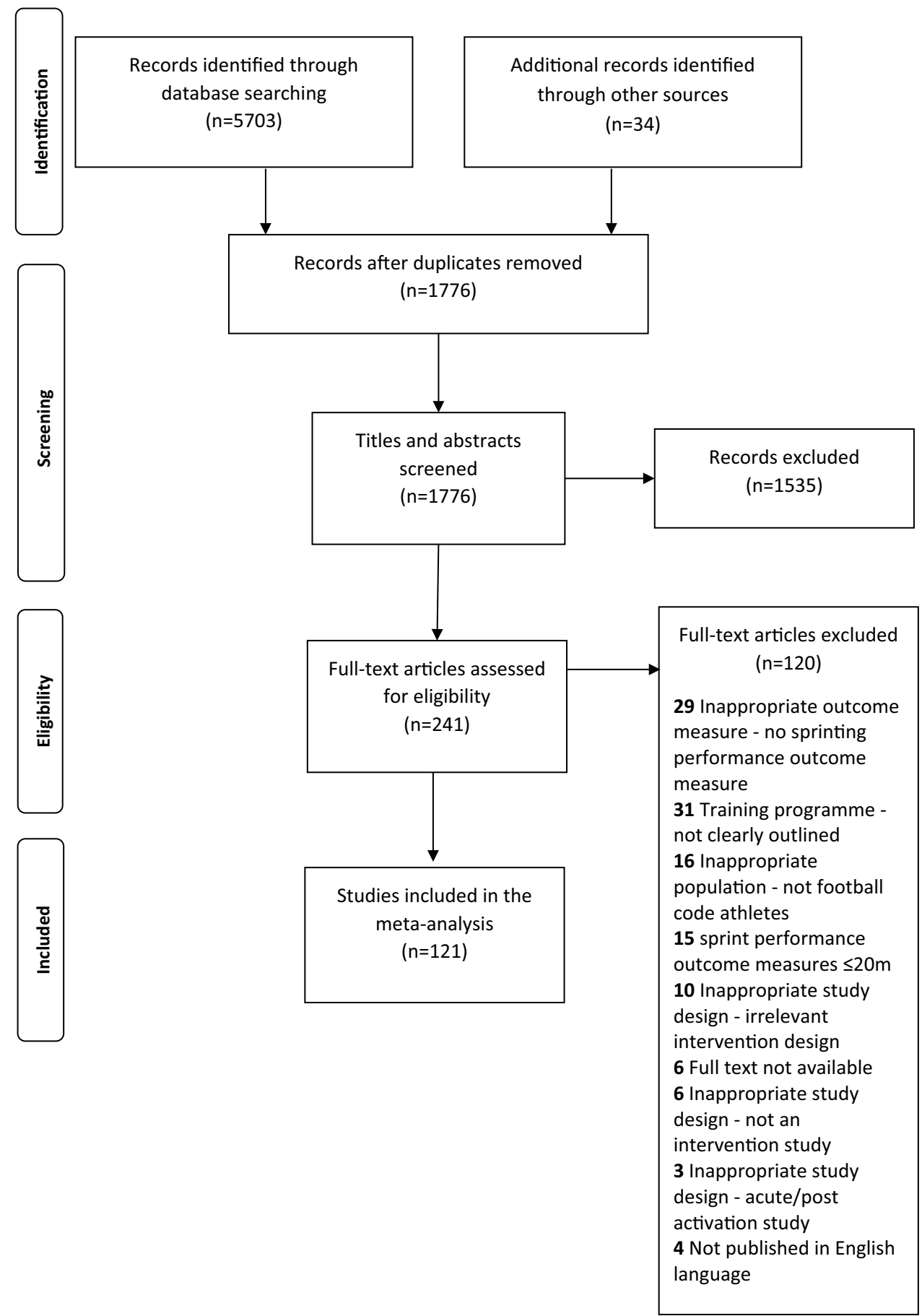

power is produced (1-1.1 $\times$ optimal power load). Exercise volume ranged from $2-5$ sets of $2-8$ repetitions/set. Plyometrics training involved low-high intensity plyometrics (e.g., ankle hops to $50 \mathrm{~cm}$ accentuated eccentric loading drop Jump @+20\% BM) 1-15 sets of 4-15 repetitions/set (10-260 foot contacts session totals) on various surfaces (grass, dry sand surface, hard and soft surfaces). Several of the sessions were performed in combination with upper body training.
Combined methods training groups consisted of various formats of both specific sprint training (primary and or secondary methods) and tertiary methods in combination (e.g., strength, power, resisted and unresisted sprint training). These were completed as individual modalities and or/ in combination (e.g., complex and contrast sets). The training was performed 1-4 day per week, with intervention periods lasting from 3 to 26 weeks (6-52 sessions). Strength training ranged from moderate-high loads (70-90\% 1RM) 
low-high volume (e.g., 1-8 sets 2-6 repetitions/set and/or $3-4$ sets of $8-12$ repetitions). Power training consisted of ballistic exercises at light to moderate loads (30-65\% 1RM or $15-100 \% \mathrm{BM}$ ) and/or velocity-based training using loads corresponding to the mass at which optimal power is produced (1-1.1 $\times$ optimal power load or $80-105 \%$ of $1 \mathrm{~m} \cdot \mathrm{s}^{-1}$ load). Repetition ranges were from 2 to 6 sets of 2 to 8 repetitions per set. This also included medicine ball throws from 3 to $12 \mathrm{~kg}$. Plyometrics sessions involved low-high intensity plyometrics (e.g., ankle hops to $75 \mathrm{~cm}$ hurdle jumps) $1-5$ sets of 3-15 repetitions per set (9-310 foot contacts session totals). The only type of surface identified was a grass track. The specific sprint training methods included single set interventions ranging from 1 to 5 repetitions short-sprint (5-20 m) or multiple set methods, ranging from 2 to 4 sets of 2 to 8 repetitions/set of medium-long distance sprints (25-40 m) (80-340 m session totals) from various starting positions. Resisted sprint loads ranged from light-very heavy loads [52]. Loads were prescribed based on percentage body mass (i.e., 5-55\%BM), absolute loads (i.e., 5-10 kg) or reduction in $V_{\max }$ corresponding with the additional resistance applied (i.e., $10 \%$ reduction in $V_{\max }$ ). A number of the sessions were performed in combination with upper body training.

\subsection{Study Quality}

The scores for the assessment of study quality according to McMaster et al. (2013) [59] are shown in Table 4, ranging from 14 to 20 with a mean score of $18.1 \pm 1.7$ demonstrating high study quality. Items 2 (subjects assigned appropriately (random/equal baseline)), 4 (control group inclusion), 6 (assessments practical) and 9 (results detailed (mean, SD, percent change, effect size)) were the most decisive factors in separating the high-quality from the low-quality studies.

\subsection{Meta-analysis}

Individual study statistics can be seen in the Electronic Supplementary Material Tables S1-S3.

\subsection{Standardised Mean Difference for 0-5 m Performance}

For 0-5 m performance, 93 training group effects were analysed from 43 original studies [41, 42, 64, 73, 77-80, 82, $88,89,94,95,98,100,101,105,110,112,114-116,120$, 122-124, 130, 131, 134, 136-138, 141, 166-169, 173, 179, 180, 183-185]. Figure 2 shows the SMD for each training type. The sport only and primary methods training failed to show statistical significance for change in $0-5 \mathrm{~m}$ performance. Combined methods showed large improvements, while combined specific, secondary and tertiary methods showed moderate performance improvements. The combined and tertiary methods were the only training methods that produced a significantly larger training effect than sport only training. All methods produced a significantly larger training effect than the primary methods, apart from the sport only group. Between-subgroup analysis was not conducted on the combined specific subgroup as only one training group was available.

\subsection{Standardised Mean Difference for $0-10 \mathrm{~m}$ Performance}

For 0-10 m performance, 189 training group effects were analysed from 85 original studies [40-42, 65, 71, 72, 75, 76, 78, 79, 83-95, 97, 99, 101-105, 107-117, 119-130, 132, 136-139, 141, 153-162, 165-169, 171, 172, 175, 176, $178,180-182,185,186]$. Figure 3 shows the SMD for each training type. The sport only training and primary methods failed to show statistical significance for change in 0-10 m performance. Combined specific methods showed large, while combined, secondary and tertiary methods showed moderate performance improvement. The combined, secondary and tertiary methods produced a significantly larger training effect than sport only and primary training methods. Between-subgroup analysis was not conducted on the combined specific subgroup as only two training groups where available.

\subsection{Standardised Mean Difference for 0-20 m Performance}

For 0-20 m performance, 210 training group effects were analysed from 85 original studies [40-42, 64-66, 72-74, 78-81, 84, 86, 87, 89, 92-98, 101, 103, 106, 107, 109-111, 117, 118, 120-124, 127-131, 134-143, 145-153, 155-158, 161-164, 166-171, 173-175, 177, 179, 180, 184, 185, 187] Fig. 4 shows the SMD for each training type. The sport only training, combined specific and primary methods training failed to show statistical significance for change in 0-20 m performance. Combined, secondary and tertiary methods showed moderate performance improvement. Combined and tertiary methods produced significantly larger training effects than sport only and primary methods training groups. The secondary training methods produced a significantly larger training effect than sport only training.

\subsection{Heterogeneity}

The degree of overall heterogeneity was high for all outcome measures between studies $I^{2}(>75 \%)$. 
Table 4 Methodological quality scale scores

\begin{tabular}{|c|c|c|c|c|c|c|c|c|c|c|c|}
\hline \multirow[t]{2}{*}{ Study } & \multicolumn{10}{|c|}{ Question number } & \multirow[t]{2}{*}{ Score } \\
\hline & 1 & 2 & 3 & 4 & 5 & 6 & 7 & 8 & 9 & 10 & \\
\hline Alves et al. (2010) [73] & 2 & 2 & 2 & 2 & 2 & 2 & 2 & 2 & 0 & 2 & 18 \\
\hline Arcos et al. (2014) [118] & 2 & 2 & 2 & 0 & 2 & 2 & 2 & 2 & 2 & 2 & 18 \\
\hline Asadi et al. (2018) [74] & 2 & 2 & 2 & 2 & 2 & 2 & 2 & 2 & 2 & 2 & 20 \\
\hline Barr et al. (2015) [75] & 2 & 2 & 2 & 2 & 2 & 2 & 2 & 2 & 2 & 2 & 20 \\
\hline Beato et al. (2018) [76] & 2 & 2 & 2 & 0 & 2 & 2 & 2 & 2 & 2 & 2 & 18 \\
\hline Bianchi et al. (2019) [183] & 2 & 2 & 2 & 0 & 2 & 2 & 2 & 2 & 2 & 2 & 18 \\
\hline Borges et al. (2016) [77] & 2 & 2 & 2 & 0 & 2 & 2 & 2 & 2 & 0 & 2 & 16 \\
\hline Bouguezzi et al. (2018) [78] & 2 & 2 & 2 & 0 & 2 & 2 & 2 & 2 & 2 & 2 & 18 \\
\hline Bremec (2018) [79] & 2 & 2 & 2 & 2 & 2 & 2 & 2 & 2 & 2 & 2 & 20 \\
\hline Brito et al. (2014) [80] & 2 & 2 & 2 & 2 & 2 & 2 & 2 & 2 & 2 & 2 & 20 \\
\hline Cavaco et al. (2014) [81] & 2 & 2 & 2 & 2 & 2 & 2 & 2 & 2 & 0 & 0 & 16 \\
\hline Chelly et al. (2010) [82] & 2 & 2 & 2 & 2 & 2 & 2 & 2 & 2 & 2 & 2 & 20 \\
\hline Christou et al. (2006) [83] & 2 & 2 & 2 & 2 & 2 & 2 & 2 & 2 & 2 & 2 & 20 \\
\hline Comfort et al. (2012) [84] & 2 & 0 & 2 & 0 & 2 & 2 & 2 & 2 & 0 & 2 & 14 \\
\hline Coratella et al. (2019) [85] & 2 & 2 & 2 & 2 & 2 & 2 & 2 & 2 & 2 & 2 & 20 \\
\hline Corrêa et al. (2016) [184] & 2 & 0 & 2 & 0 & 2 & 2 & 2 & 2 & 0 & 2 & 14 \\
\hline Coutts et al. (2004) [72] & 2 & 2 & 2 & 0 & 2 & 2 & 2 & 2 & 0 & 2 & 16 \\
\hline Coutts et al. (2007) [71] & 2 & 0 & 2 & 0 & 2 & 2 & 2 & 2 & 0 & 2 & 14 \\
\hline De Hoyo et al. (2015) [86] & 2 & 0 & 2 & 2 & 2 & 2 & 2 & 2 & 0 & 2 & 16 \\
\hline De Hoyo et al. (2016) [87] & 2 & 2 & 2 & 0 & 2 & 2 & 2 & 2 & 2 & 2 & 18 \\
\hline De Villarreal et al. (2015) [88] & 2 & 2 & 2 & 2 & 2 & 2 & 2 & 2 & 2 & 2 & 20 \\
\hline Derakhti et al. (2018) [89] & 2 & 2 & 2 & 2 & 2 & 2 & 2 & 2 & 2 & 2 & 20 \\
\hline Douglas et al. (2018) [40] & 2 & 2 & 2 & 2 & 2 & 2 & 2 & 2 & 2 & 2 & 20 \\
\hline Enoksen et al. (2013) [90] & 2 & 2 & 2 & 2 & 2 & 2 & 2 & 2 & 2 & 2 & 20 \\
\hline Faude et al. (2013) [91] & 2 & 2 & 2 & 2 & 2 & 2 & 2 & 2 & 2 & 2 & 20 \\
\hline Franco-Márquez et al. (2015) [92] & 2 & 2 & 2 & 2 & 2 & 2 & 2 & 2 & 2 & 2 & 20 \\
\hline Gabbett et al. (2008) [93] & 2 & 0 & 2 & 0 & 2 & 2 & 2 & 2 & 1 & 2 & 15 \\
\hline Garciª-Pinillos et al. (2014) [94] & 2 & 2 & 2 & 2 & 2 & 2 & 2 & 2 & 0 & 2 & 18 \\
\hline Gil et al. (2018) [95] & 2 & 2 & 2 & 0 & 2 & 2 & 2 & 2 & 2 & 2 & 18 \\
\hline González-Badillo et al. (2015) [96] & 2 & 0 & 2 & 2 & 0 & 2 & 2 & 2 & 0 & 2 & 14 \\
\hline González-García et al. (2019) [97] & 2 & 2 & 2 & 2 & 2 & 2 & 2 & 2 & 1 & 2 & 19 \\
\hline Gorostiaga et al. (2004) [98] & 2 & 2 & 2 & 2 & 2 & 2 & 2 & 2 & 0 & 2 & 18 \\
\hline Griffiths et al. (2019) [99] & 2 & 2 & 2 & 0 & 2 & 2 & 2 & 2 & 2 & 2 & 18 \\
\hline Hammami et al. (2016) 1 [101] & 2 & 2 & 2 & 2 & 2 & 2 & 2 & 2 & 0 & 2 & 18 \\
\hline Hammami et al. (2016) 2 [102] & 2 & 2 & 2 & 0 & 2 & 2 & 2 & 2 & 2 & 2 & 18 \\
\hline Hammami et al. (2018) [100] & 2 & 2 & 2 & 2 & 2 & 2 & 2 & 2 & 2 & 2 & 20 \\
\hline Harries et al. (2017) [103] & 2 & 2 & 2 & 2 & 2 & 2 & 2 & 2 & 2 & 2 & 20 \\
\hline Harris et al. (2008) [104] & 2 & 2 & 2 & 0 & 2 & 0 & 2 & 2 & 0 & 2 & 14 \\
\hline Harrison and Bourke (2009) [105] & 2 & 2 & 2 & 2 & 2 & 2 & 2 & 2 & 0 & 2 & 18 \\
\hline Haugen et al. (2014) [106] & 2 & 2 & 2 & 2 & 2 & 2 & 2 & 2 & 0 & 2 & 18 \\
\hline Haugen et al. (2015) [66] & 2 & 2 & 2 & 2 & 2 & 2 & 2 & 2 & 0 & 2 & 18 \\
\hline Helgerud et al. (2011) [185] & 2 & 0 & 2 & 0 & 2 & 2 & 2 & 2 & 0 & 2 & 14 \\
\hline Impellizzeri et al. (2007) [107] & 2 & 2 & 2 & 0 & 2 & 2 & 2 & 2 & 2 & 2 & 18 \\
\hline Ishøi et al. (2017) [108] & 2 & 2 & 2 & 0 & 2 & 2 & 2 & 2 & 2 & 2 & 18 \\
\hline Kobal et al. (2017) 1 [109] & 2 & 2 & 2 & 0 & 2 & 2 & 2 & 2 & 0 & 2 & 16 \\
\hline Kobal et al. (2017) 2 [110] & 2 & 2 & 2 & 0 & 2 & 2 & 2 & 2 & 2 & 2 & 18 \\
\hline Koundourakis et al. (2014) [111] & 2 & 0 & 1 & 2 & 2 & 2 & 2 & 2 & 0 & 2 & 15 \\
\hline Krommes et al. (2017) [112] & 2 & 2 & 2 & 2 & 2 & 2 & 2 & 2 & 2 & 2 & 20 \\
\hline Lago-Fuentes et al. (2018) [113] & 2 & 2 & 2 & 0 & 2 & 2 & 2 & 2 & 1 & 2 & 17 \\
\hline
\end{tabular}


Table 4 (continued)

\begin{tabular}{|c|c|c|c|c|c|c|c|c|c|c|c|}
\hline \multirow[t]{2}{*}{ Study } & \multicolumn{10}{|c|}{ Question number } & \multirow[t]{2}{*}{ Score } \\
\hline & 1 & 2 & 3 & 4 & 5 & 6 & 7 & 8 & 9 & 10 & \\
\hline Lockie et al. (2012) 1 [115] & 2 & 2 & 2 & 0 & 2 & 2 & 2 & 2 & 2 & 2 & 18 \\
\hline Lockie et al. (2012) 2 [114] & 2 & 2 & 2 & 0 & 2 & 2 & 2 & 2 & 2 & 2 & 18 \\
\hline Lockie et al. (2014) [116] & 2 & 2 & 2 & 0 & 2 & 2 & 2 & 2 & 2 & 2 & 18 \\
\hline Lopez-Segovia et al. (2010) [117] & 2 & 2 & 2 & 2 & 2 & 2 & 2 & 2 & 2 & 2 & 20 \\
\hline Loturco et al. (2013) [119] & 2 & 2 & 2 & 0 & 2 & 2 & 2 & 2 & 0 & 2 & 16 \\
\hline Loturco et al. (2015) 1 [120] & 2 & 2 & 2 & 0 & 2 & 2 & 2 & 2 & 2 & 2 & 18 \\
\hline Loturco et al. (2015) 2 [121] & 2 & 2 & 2 & 0 & 2 & 2 & 2 & 2 & 2 & 2 & 18 \\
\hline Loturco et al. (2015) 3 [122] & 2 & 2 & 2 & 0 & 2 & 2 & 2 & 2 & 2 & 2 & 18 \\
\hline Loturco et al. (2016) 1 [123] & 2 & 2 & 2 & 0 & 2 & 2 & 2 & 2 & 2 & 2 & 18 \\
\hline Loturco et al. (2016) 2 [41] & 2 & 2 & 2 & 0 & 2 & 2 & 2 & 2 & 0 & 2 & 16 \\
\hline Loturco et al. (2017) [124] & 2 & 2 & 2 & 0 & 2 & 2 & 2 & 2 & 0 & 2 & 16 \\
\hline Loturco et al. (2019) [186] & 2 & 2 & 2 & 0 & 2 & 2 & 2 & 2 & 2 & 2 & 18 \\
\hline Manolopoulos et al. (2004) [125] & 2 & 2 & 2 & 2 & 2 & 2 & 2 & 2 & 0 & 2 & 18 \\
\hline Manouras et al. (2016) [126] & 2 & 2 & 2 & 2 & 2 & 2 & 2 & 2 & 0 & 2 & 18 \\
\hline Marques et al. (2019) [159] & 2 & 2 & 2 & 2 & 2 & 2 & 2 & 2 & 2 & 2 & 20 \\
\hline Mathisen and Danielsen (2014) [127] & 2 & 2 & 1 & 2 & 2 & 2 & 2 & 2 & 0 & 2 & 17 \\
\hline Mathisen and Pettersen (2015) [128] & 2 & 2 & 1 & 2 & 2 & 2 & 2 & 2 & 0 & 2 & 17 \\
\hline McMaster et al. (2014) [129] & 2 & 2 & 2 & 0 & 2 & 2 & 2 & 2 & 2 & 2 & 18 \\
\hline McMorrow et al. (2019) [130] & 2 & 2 & 2 & 0 & 2 & 2 & 2 & 2 & 2 & 2 & 18 \\
\hline Mendiguchia et al. (2015) [131] & 2 & 2 & 2 & 2 & 2 & 2 & 2 & 2 & 2 & 2 & 20 \\
\hline Meylan and Malatesta (2009) [132] & 2 & 2 & 2 & 2 & 2 & 2 & 2 & 2 & 0 & 2 & 18 \\
\hline Michailidis et al. (2019) [133] & 2 & 2 & 2 & 2 & 2 & 2 & 2 & 2 & 0 & 2 & 18 \\
\hline Morin et al. (2017) [134] & 2 & 2 & 2 & 2 & 2 & 2 & 2 & 2 & 2 & 2 & 20 \\
\hline Mujika et al. (2009) [135] & 2 & 2 & 2 & 0 & 2 & 2 & 2 & 2 & 0 & 2 & 16 \\
\hline Nakamura et al. (2012) [136] & 2 & 0 & 2 & 2 & 2 & 2 & 2 & 2 & 2 & 2 & 18 \\
\hline Negra et al. (2016) [137] & 2 & 2 & 2 & 2 & 2 & 2 & 2 & 2 & 0 & 2 & 18 \\
\hline Negra et al. (2019) [138] & 2 & 2 & 2 & 0 & 2 & 2 & 2 & 2 & 2 & 2 & 18 \\
\hline Nonnato et al. (2020) [181] & 2 & 2 & 2 & 2 & 2 & 2 & 2 & 2 & 2 & 2 & 20 \\
\hline Ozbar (2015) [139] & 2 & 2 & 2 & 2 & 2 & 2 & 2 & 2 & 2 & 2 & 20 \\
\hline Ozbar et al. (2014) [140] & 2 & 2 & 2 & 2 & 2 & 2 & 2 & 2 & 0 & 2 & 18 \\
\hline Pienaar and Coetzee (2013) [141] & 2 & 2 & 2 & 2 & 2 & 2 & 2 & 2 & 2 & 2 & 20 \\
\hline Ramirez-Campillo et al. (2013) [142] & 2 & 2 & 2 & 2 & 2 & 2 & 2 & 2 & 1 & 2 & 19 \\
\hline Ramirez-Campillo et al. (2014) 1 [143] & 2 & 2 & 2 & 2 & 2 & 2 & 2 & 2 & 2 & 2 & 20 \\
\hline Ramirez-Campillo et al. (2014) 2 [144] & 2 & 2 & 1 & 2 & 2 & 2 & 2 & 2 & 1 & 2 & 18 \\
\hline Ramirez-Campillo et al. (2015) 1 [146] & 2 & 2 & 2 & 2 & 2 & 2 & 2 & 2 & 2 & 2 & 20 \\
\hline Ramirez-Campillo et al. (2015) 2 [145] & 2 & 2 & 2 & 2 & 2 & 2 & 2 & 2 & 2 & 2 & 20 \\
\hline Ramirez-Campillo et al. (2016) [147] & 2 & 2 & 2 & 2 & 2 & 2 & 2 & 2 & 0 & 2 & 18 \\
\hline Ramirez-Campillo et al. (2018) 1 [150] & 2 & 2 & 2 & 2 & 2 & 2 & 2 & 2 & 2 & 2 & 20 \\
\hline Ramirez-Campillo et al. (2018) 2 [149] & 2 & 2 & 2 & 2 & 2 & 2 & 2 & 2 & 2 & 2 & 20 \\
\hline Ramirez-Campillo et al. (2018) 3 [148] & 2 & 2 & 2 & 2 & 2 & 2 & 2 & 2 & 1 & 2 & 19 \\
\hline Ramirez-Campillo et al. (2018) 4 [151] & 2 & 2 & 2 & 2 & 2 & 2 & 2 & 2 & 1 & 2 & 19 \\
\hline Ramirez-Campillo et al. (2019) [152] & 2 & 2 & 2 & 2 & 2 & 2 & 2 & 2 & 2 & 2 & 20 \\
\hline Randell et al. (2011) [153] & 2 & 2 & 2 & 2 & 2 & 2 & 2 & 2 & 2 & 2 & 20 \\
\hline Rey et al. (2017) [154] & 2 & 2 & 2 & 2 & 2 & 2 & 2 & 2 & 2 & 2 & 20 \\
\hline Rimmer and Sleivert (2000) [155] & 2 & 2 & 2 & 2 & 2 & 2 & 2 & 2 & 0 & 2 & 18 \\
\hline Rodriguez-Rosell et al. (2016) [156] & 2 & 2 & 2 & 2 & 2 & 2 & 2 & 2 & 2 & 2 & 20 \\
\hline Rodriguez-Rosell et al. (2017) 1 [157] & 2 & 2 & 2 & 2 & 2 & 2 & 2 & 2 & 2 & 2 & 20 \\
\hline Rodriguez-Rosell et al. (2017) 2 [158] & 2 & 2 & 2 & 2 & 2 & 2 & 2 & 2 & 2 & 2 & 20 \\
\hline Ronnestad et al. (2008) [160] & 2 & 2 & 2 & 2 & 2 & 2 & 2 & 2 & 0 & 2 & 18 \\
\hline
\end{tabular}


Table 4 (continued)

\begin{tabular}{|c|c|c|c|c|c|c|c|c|c|c|c|}
\hline \multirow[t]{2}{*}{ Study } & \multicolumn{10}{|c|}{ Question number } & \multirow[t]{2}{*}{ Score } \\
\hline & 1 & 2 & 3 & 4 & 5 & 6 & 7 & 8 & 9 & 10 & \\
\hline Ross et al. (2015) [182] & 2 & 2 & 2 & 0 & 2 & 2 & 2 & 2 & 2 & 2 & 18 \\
\hline Sánchez-Sánchez et al. (2015) [161] & 2 & 2 & 2 & 2 & 2 & 2 & 2 & 2 & 0 & 2 & 18 \\
\hline Scott et al. (2017) [162] & 2 & 2 & 2 & 2 & 2 & 2 & 2 & 2 & 0 & 2 & 18 \\
\hline Seitz (2015) [164] & 2 & 2 & 2 & 0 & 2 & 2 & 2 & 2 & 2 & 2 & 18 \\
\hline Shalfawi et al. (2012) [163] & 2 & 2 & 2 & 2 & 2 & 2 & 2 & 2 & 2 & 2 & 20 \\
\hline Singh et al. (2014) [165] & 2 & 0 & 2 & 2 & 2 & 0 & 2 & 2 & 0 & 0 & 12 \\
\hline Söhnlein et al. (2014) [166] & 2 & 0 & 2 & 2 & 2 & 2 & 2 & 2 & 2 & 2 & 18 \\
\hline Spinks et al. (2007) [42] & 2 & 2 & 2 & 2 & 2 & 2 & 2 & 2 & 0 & 2 & 18 \\
\hline Styles et al. (2016) [167] & 2 & 0 & 2 & 0 & 2 & 2 & 2 & 2 & 2 & 2 & 16 \\
\hline Suarez-Arrones et al. (2019) [168] & 2 & 2 & 2 & 2 & 2 & 2 & 2 & 2 & 2 & 2 & 20 \\
\hline Thomas et al. (2009) [169] & 2 & 2 & 2 & 0 & 2 & 2 & 2 & 2 & 0 & 2 & 16 \\
\hline Tønnessen et al. (2011) [170] & 2 & 2 & 2 & 2 & 2 & 2 & 2 & 2 & 2 & 2 & 20 \\
\hline Torres-Torrelo et al. (2017) [171] & 2 & 2 & 2 & 2 & 2 & 2 & 2 & 2 & 2 & 2 & 20 \\
\hline Tous-Fajardo et al. (2016) [172] & 2 & 0 & 2 & 2 & 2 & 2 & 2 & 2 & 0 & 2 & 16 \\
\hline Upton (2011) [173] & 2 & 2 & 2 & 0 & 2 & 2 & 2 & 2 & 0 & 2 & 16 \\
\hline Venturelli et al. (2008) [177] & 2 & 2 & 2 & 0 & 2 & 2 & 2 & 2 & 0 & 2 & 16 \\
\hline Vera-Assaoka et al. (2019) [174] & 2 & 2 & 2 & 2 & 2 & 2 & 2 & 2 & 2 & 2 & 20 \\
\hline Weakley et al. (2019) [175] & 2 & 2 & 2 & 2 & 2 & 2 & 2 & 2 & 2 & 2 & 20 \\
\hline West et al. (2013) [176] & 2 & 2 & 2 & 0 & 2 & 2 & 2 & 2 & 0 & 2 & 16 \\
\hline Winwood et al. (2015) [64] & 2 & 2 & 2 & 0 & 2 & 2 & 2 & 2 & 0 & 2 & 16 \\
\hline Wong et al. (2010) [178] & 2 & 0 & 2 & 2 & 2 & 2 & 2 & 2 & 0 & 2 & 16 \\
\hline Yanci et al. (2016) [179] & 2 & 2 & 2 & 0 & 2 & 2 & 2 & 2 & 2 & 2 & 18 \\
\hline Zghal et al. (2019) [180] & 2 & 2 & 2 & 2 & 2 & 2 & 2 & 2 & 2 & 2 & 20 \\
\hline
\end{tabular}

$0=$ clear no $; 1=$ maybe and $2=$ clearly yes

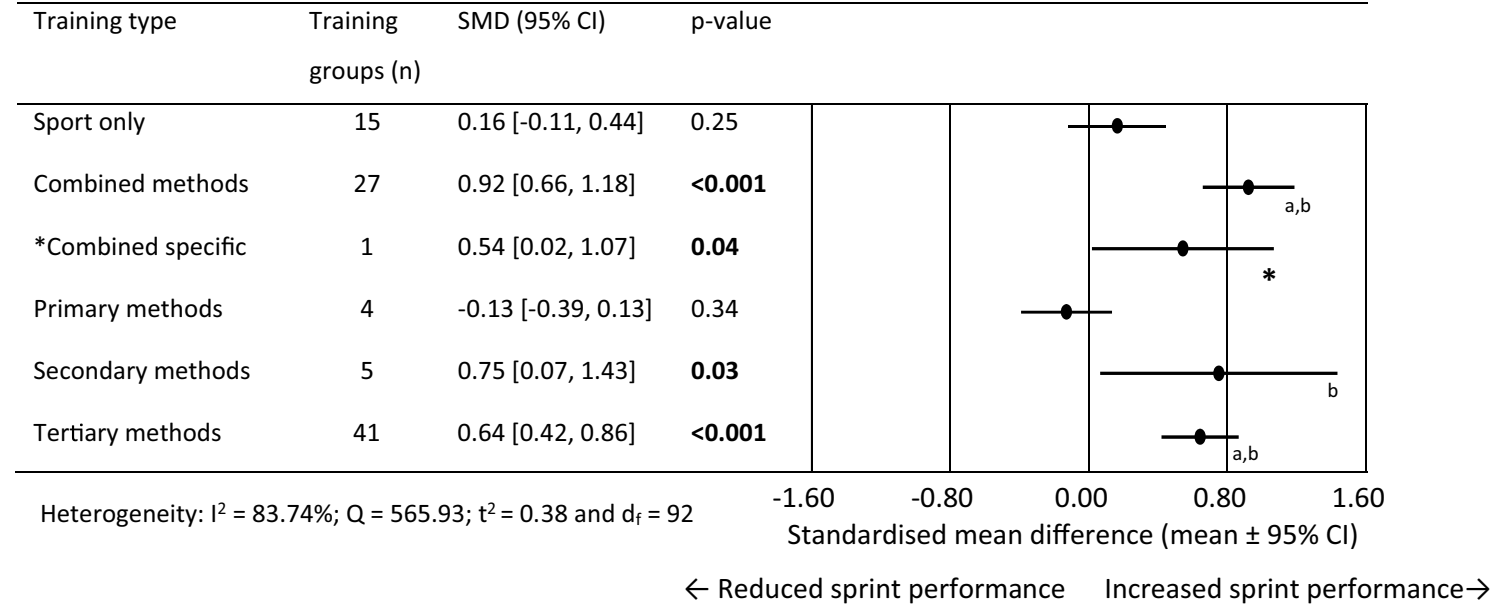

Fig. 2 Forest plots showing the standardised mean differences (mean $\pm 95 \% \mathrm{CI}$ ) for the studies evaluating the between training group effects on $0-5 \mathrm{~m}$ sprint performance. Bold font $=p<0.05$ and *less than 3 studies in this training group. ${ }^{\text {a }}$ Significantly different to sport

\subsection{Sensitivity}

Sensitivity analysis revealed minor changes only, for the majority of performance variables, and these changes did only training $p<0.05$, 'bignificantly different to primary methods training methods $p<0.05$. SMD standardised mean differences and $C I$ confidence interval

not substantially impact the overall mean effect. Combined specific and secondary training methods were sensitive to the exclusion of one or more studies independently and in turn, moderated the statistical interpretation of the results. 
Removal of one of the three combined specific 0-20 m studies [127] moderated the statistical significance from nonsignificant $(p>0.05)$ to significant $(p<0.05)$. Removal of three of the four $0-5 \mathrm{~m}$ and $0-20 \mathrm{~m}$ studies $[79,89,173]$ and two of the three $0-10 \mathrm{~m}$ studies $[79,89,173]$ moderated the statistical significance from significant to non-significant.

\subsection{Evaluation of Small Study Effects}

Inspection of the funnel plot and Egger's regression intercept revealed a large and statistically significant Egger statistic indicating that there was evidence of small study effects for the $0-5 \mathrm{~m}$ (intercept $5.23,95 \%$ CI $3.51-6.95 ; p<0.001$ ), $0-10 \mathrm{~m}$ (intercept $4.61,95 \%$ CI $3.32-5.91 ; p<0.001$ ) and $0-20 \mathrm{~m}$ (intercept $4.66,95 \%$ CI $3.58-5.74 ; p<0.001$ ). The SMD between pre- and post-intervention sprint performance was not considered symmetrical, suggesting the presence of significant publication bias [188].

\subsection{Moderator Variables}

Table 5 presents the subgroup analysis assessing potential moderating factors for short-sprint performance $(0-5 \mathrm{~m}$, $0-10 \mathrm{~m}$ and $0-20 \mathrm{~m})$. Regarding the population characteristics, between-subgroup analysis significant $(p<0.05)$ identified that football code, age and phase of training all moderated overall magnitude of training effects. There was no statistical difference between sex and playing standard groups.

\section{Discussion}

\subsection{Overview of the Main Findings}

Multiple training methods are recommended for improving short-sprint performance due to its importance in the football codes [39, 43, 46, 48, 50-57]. This review is the first to (1) systematically review the scientific literature evaluating training interventions upon short-sprint performance (0-5 m, 0-10 $\mathrm{m}$ and 0-20 m) in football code athletes, (2) undertake a meta-analysis to assess the magnitude of change in short-sprint performance following training interventions and (3) identify how moderator variables (i.e., football code, sex, playing standard, age and phase of season) affect the training response. The review analysed 121 studies [40-42, 64-66, 71-181], totalling 3419 athletes short-sprint performance providing the largest systematic evidence base for enhancing short-sprint performance in football code athletes (i.e., the previous largest sample is 48 studies from a mixed sample) [39, 43, 46, 48, 50-57, 59].

In summary, the meta-analysis showed that short-sprint performance can be enhanced through combined, secondary and tertiary training methods. Combined specific training methods also showed moderate significant improvements in short-sprint performance at $0-5 \mathrm{~m}$ and $0-10 \mathrm{~m}$. These findings support previous literature stating that football code athletes sprint performance can be enhanced concurrently alongside football code specific training [39]. Sport only training and primary training methods showed no effect on short-sprint performance, suggesting such training alone is insufficient to improve short-sprint performance. Betweensubgroup analysis identified that football code, age, playing

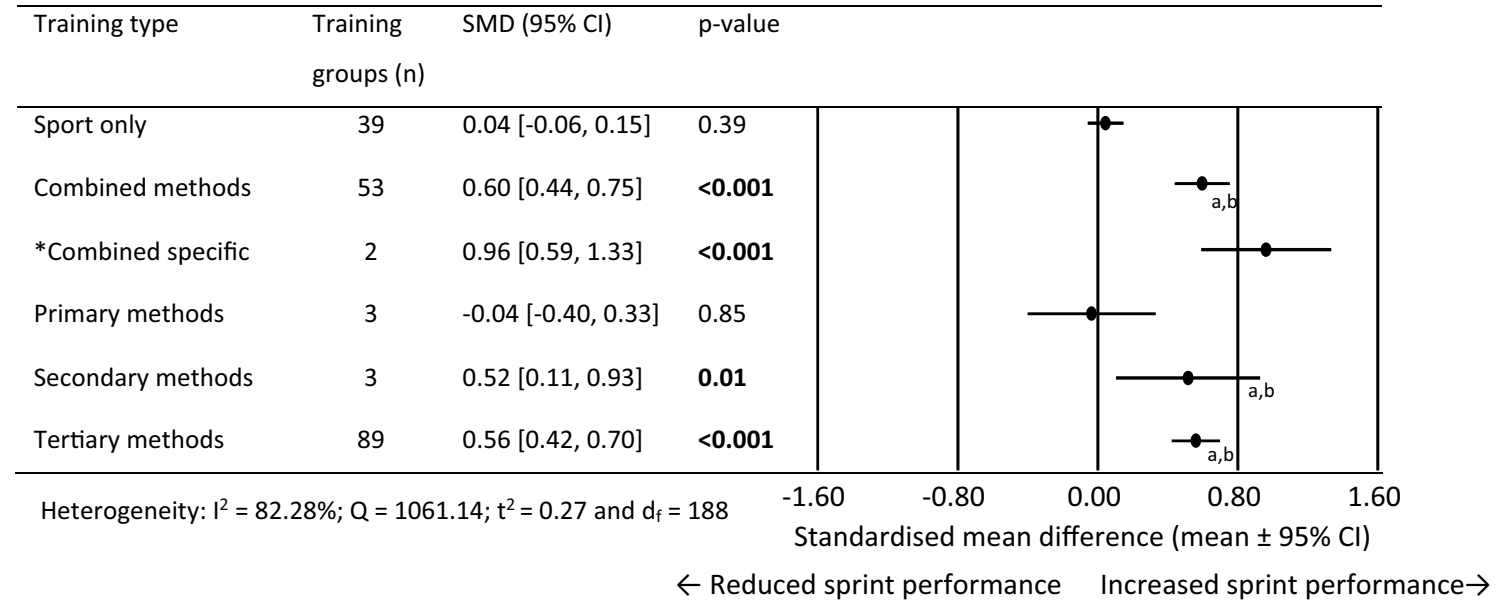

Fig. 3 Forest plots showing the standardised mean differences (mean $\pm 95 \% \mathrm{CI}$ ) for the studies evaluating the between training group effects on $0-10 \mathrm{~m}$ sprint performance. Bold font $=p<0.05$ and *less

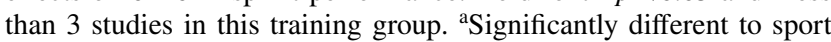

only training $p<0.05$, ${ }^{\mathrm{b}}$ Significantly different to primary methods training methods $p<0.05$. SMD standardised mean differences and $C I$ confidence interval 


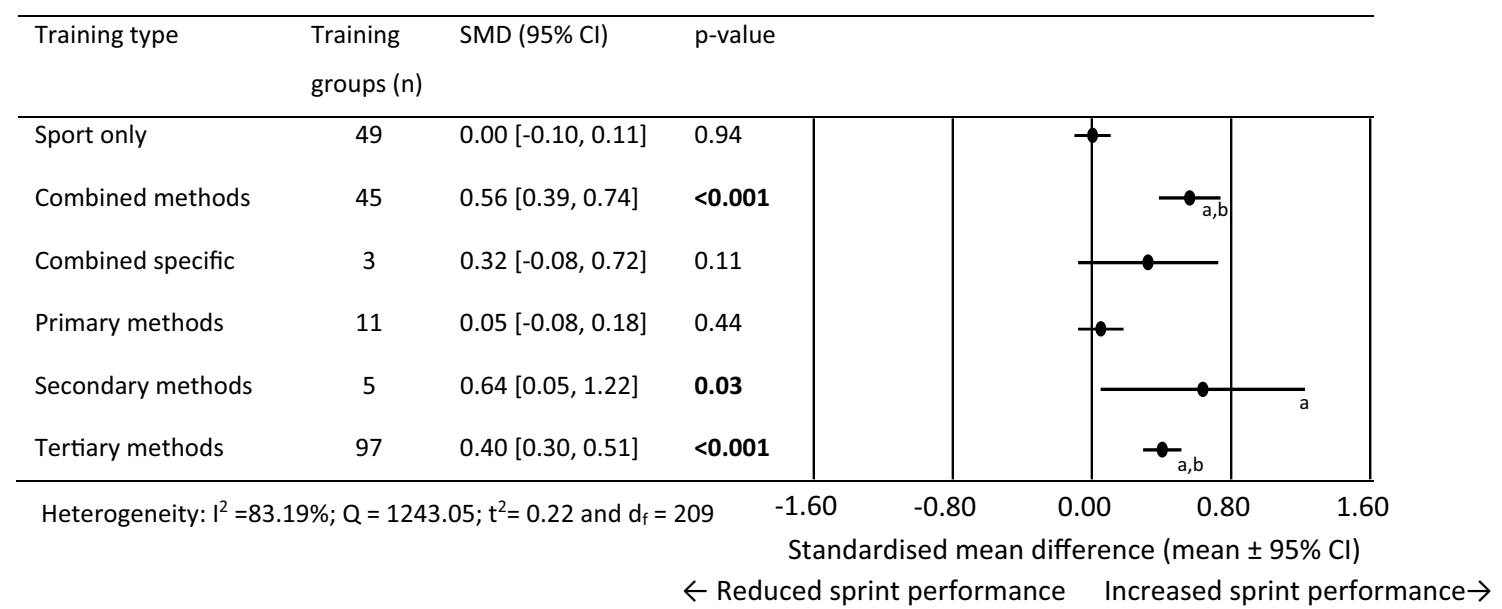

Fig. 4 Forest plots showing the standardised mean differences (mean $\pm 95 \% \mathrm{CI}$ ) for the studies evaluating the between training group effects on 0-20 m sprint performance. ${ }^{a}$ Significantly different to sport

standard and phase of training all moderated overall magnitude of training effects. Athlete's sex demonstrated no significant difference between-subgroups.

\subsection{Summary of Interventions to Develop Short-Sprint Performance}

The included 121 studies were categorised into six training mode categories resulting in 286 training groups (i.e., sport only, $n=64$; combined methods, $n=76$; combined specific methods, $n=3$; primary methods, $n=11$, secondary methods, $n=6$; and tertiary methods, $n=124$ ). This highlights the volume of tertiary method training studies and the reported gap in the available literature to support specific sprint training methods (primary, secondary and combined specific training methods) in football code athletes [48, 52]. The scarcity of specific sprint training method studies maybe because in practice, football code coaches typically implement tertiary training methods to develop multiple physical qualities (i.e., resistance training and plyometrics [16, 189, 190]). This is also a strength of the current systematic review as previous reviews $[43,48]$ have not considered all training undertaken by the intervention groups within their analysis (e.g., primary or secondary training groups also completing tertiary training methods $[42,105,114-116,176])$.

The degree of overall heterogeneity was high for all outcome measures between studies $\left(I^{2}>75 \%\right.$ [191]. Heterogeneity in systematic reviews is to be expected due to grouping studies together that are diverse, both clinically and methodologically [191]. The high degree of heterogeneity reflects the diversity of the training effects presented. This is likely due to wide variation in the intervention characteristics, including training principles (e.g., frequency [73], duration $[75,96]$, intensity [66, 192], volume [111], other training only training $p<0.05$, ${ }^{\mathrm{b}}$ Significantly different to primary methods training methods $p<0.05$. Bold font $=p<0.05$; SMD standardised mean differences and $C I$ confidence interval

completed), population characteristics (e.g., sex [106, 193], chronological age [157], maturation [45], code [42], playing standard [40, 97], playing position, baseline physical characteristics [182] and training experience [168]) and performance monitoring methodology (e.g., equipment [99, 105], start position [194], environmental factors [37], testing frequency and re-test time point $[195,196])$. Therefore, although the supplementary tables (Electronic Supplementary Material Tables S1-S3) provide a summary of training methods for all 121 papers included in this meta-analysis, caution is warranted when interpreting the findings of this review and their implications for practice as the variation of the effect sizes demonstrates that training response is highly individualised.

The study quality assessment demonstrated high study quality ( $18.1 \pm 1.7$, ranging from 14 to 20$)$. A methodological study scale was used to evaluate research conducted in athletic-based training environments [59], showing that to increase the quality of future studies researchers should randomise participants, include a control group, ensure appropriate testing equipment is used and provide a detailed results section. Although difficult in elite applied environments, to improve the quality of future studies, investigators should allocate subjects to training groups randomly or through group equalisation, include a control group, ensure appropriate testing equipment is used and provide a detailed results section for enhancing study quality. Most interventions were conducted within applied settings; however, several studies failed to describe the additional training or provided limited information. It is important to include any concurrent training stimuli to fully assess if there were any outside interactions with any adaptations seen following a training intervention [197]. 
Most of the training interventions have reported positive effects on sprinting capabilities leading to the assumption that sprinting performance is easily improved with a variety of methods. However, this needs to be considered from the context of the literature base. Included studies represented both youth and senior athletes from elite and sub-elite cohorts with the majority having limited previous systematic exposure to the intervention methods (e.g., [66, 74, 79, 87, 88, 92, 93, 96-98, 109, 198]). Based on the dose-response relationship and the diminishing returns principle, athletes with a relatively low training age are more likely to have greater training response [199-201]. Observations of elite

Table 5 Summary of moderator variable analysis for football code, sex and playing standard age and phase of training meta-analysis by subgroup with the sport only training groups removed

\begin{tabular}{|c|c|c|}
\hline Moderator variable & Between group differences & Subgroup standardised mean difference \\
\hline Football code & 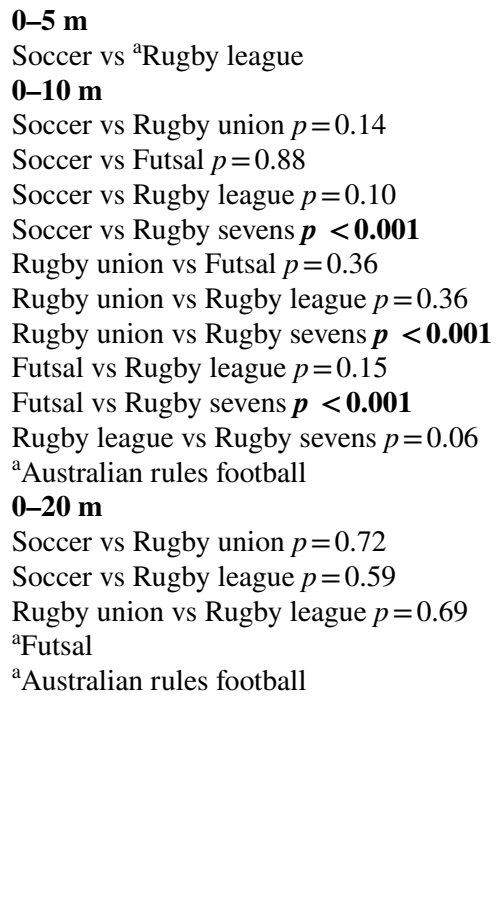 & $\begin{array}{l}\text { Soccer } \\
0-5 \mathrm{~m}(n=61 ; \mathrm{SMD}=0.66 ; 95 \% \mathrm{CI}[0.47,0.85] ; \boldsymbol{p}<\mathbf{0 . 0 0 1}) \\
0-10 \mathrm{~m}(n=99 ; \mathrm{SMD}=0.65 ; 95 \% \mathrm{CI}[0.52,0.78] ; \boldsymbol{p}<\mathbf{0 . 0 0 1}) \\
0-20 \mathrm{~m}(n=128 ; \mathrm{SMD}=0.46 ; 95 \% \mathrm{CI}[0.37,0.56] ; \boldsymbol{p}<\mathbf{0 . 0 0 1}) \\
\text { Rugby union } \\
0-5 \mathrm{~m}(\mathrm{~N} / \mathrm{A}) \\
0-10 \mathrm{~m}(n=8 ; \mathrm{SMD}=0.48 ; 95 \% \mathrm{CI}[0.31,0.66] ; \boldsymbol{p}<\mathbf{0 . 0 0 1}) \\
0-20 \mathrm{~m}(n=6 ; \mathrm{SMD}=0.43 ; 95 \% \mathrm{CI}[0.24,0.61] ; \boldsymbol{p}<\mathbf{0 . 0 0 1}) \\
\text { Futsal } \\
0-5 \mathrm{~m}(\mathrm{~N} / \mathrm{A}) \\
0-10 \mathrm{~m}(n=5 ; \mathrm{SMD}=0.68 ; 95 \% \mathrm{CI}[0.30,1.06] ; \boldsymbol{p}<\mathbf{0 . 0 0 1}) \\
{ }^{\mathrm{a}} 0-20 \mathrm{~m}(n=2 ; \mathrm{SMD}=0.34 ; 95 \% \mathrm{CI}[0.05,0.63] \boldsymbol{p}=\mathbf{0 . 0 2}) \\
\text { Rugby league } \\
{ }^{\mathrm{a}} 0-5 \mathrm{~m}(n=1 ; \mathrm{SMD}=1.19 ; 95 \% \mathrm{CI}[0.72,1.65] ; \boldsymbol{p}<\mathbf{0 . 0 0 1}) \\
0-10 \mathrm{~m}(n=10 ; \mathrm{SMD}=0.27 ; 95 \% \mathrm{CI}[-0.16,0.69] ; p=0.22) \\
0-20 \mathrm{~m}(n=9 ; \mathrm{SMD}=0.31 ; 95 \% \mathrm{CI}[-0.20,0.83] ; p=0.24)) \\
\text { Rugby sevens } \\
0-5 \mathrm{~m}(\mathrm{~N} / \mathrm{A}) \\
0-10 \mathrm{~m}(n=4 ; \mathrm{SMD}=-0.23 ; 95 \% \mathrm{CI}[-0.52,0.07] ; p=0.14) \\
0-20 \mathrm{~m}(\mathrm{~N} / \mathrm{A}) \\
\text { Australian rules football } \\
0-5 \mathrm{~m}(\mathrm{~N} / \mathrm{A}) \\
\text { a } 0-10 \mathrm{~m}(n=2 ; \mathrm{SMD}=-0.59 ; 95 \% \mathrm{CI}[-0.96,-0.21] ; \boldsymbol{p} \\
<\mathbf{0 . 0 0 1}) \\
\text { a0-20 m }(n=2 ; \mathrm{SMD}=-0.27 ; 95 \% \mathrm{CI}[-0.59,0.06] ; p=0.11)\end{array}$ \\
\hline Sex & $\begin{array}{l}\mathbf{0 - 5} \mathbf{~ m} \\
\text { Male vs female } p=0.07 \\
\mathbf{0 - 1 0} \mathbf{~ m} \\
\text { Male vs female } p=0.23 \\
\mathbf{0 - 2 0} \mathbf{~ m} \\
\text { Male vs female } p=0.06\end{array}$ & $\begin{array}{l}\text { Male } \\
0-5 \mathrm{~m}(n=75 ; \mathrm{SMD}=0.70 ; 95 \% \mathrm{CI}[0.54,0.86]) \boldsymbol{p}<\mathbf{0 . 0 0 1} \\
0-10 \mathrm{~m}(n=142 ; \mathrm{SMD}=0.55 ; 95 \% \mathrm{CI}[0.45,0.65]) \boldsymbol{p}<\mathbf{0 . 0 0 1} \\
0-20 \mathrm{~m}(n=148 ; \mathrm{SMD}=0.40 ; 95 \% \text { CI }[0.31,0.49]) \boldsymbol{p}<\mathbf{0 . 0 0 1} \\
\text { Female } \\
0-5 \mathrm{~m}(n=3 ; \mathrm{SMD}=0.88 ; 95 \% \mathrm{CI}[-0.40,2.15]) p=0.18 \\
0-10 \mathrm{~m}(n=8 ; \mathrm{SMD}=0.85 ; 95 \% \mathrm{CI}[0.36,1.34] ; \boldsymbol{p}<\mathbf{0 . 0 1}) \\
0-20 \mathrm{~m}(n=12 ; \mathrm{SMD}=0.84 ; 95 \% \text { CI }[0.40,1.28] ; \boldsymbol{p}<\mathbf{0 . 0 0 1}\end{array}$ \\
\hline Playing standard & $\begin{array}{l}\mathbf{0 - 5} \mathbf{~ m} \\
\text { Elite vs sub-elite } \boldsymbol{p}=\mathbf{0 . 0 4} \\
\mathbf{0 - 1 0 ~ \mathbf { ~ }} \\
\text { (Elite vs sub-elite) } p=0.23 \\
\mathbf{0 - 2 0} \mathbf{~ m} \\
\text { Elite vs sub-elite } p=0.08\end{array}$ & $\begin{array}{l}\text { Elite } \\
0-5 \mathrm{~m}(n=50 ; \mathrm{SMD}=0.65 ; 95 \% \text { CI }[0.44,0.85] ; \boldsymbol{p}<\mathbf{0 . 0 0 1}) \\
0-10 \mathrm{~m}(n=104 ; \mathrm{SMD}=0.56 ; 95 \% \text { CI }[0.43,0.68] ; \boldsymbol{p}<\mathbf{0 . 0 0 1} \\
0-20 \mathrm{~m}(n=109 ; \mathrm{SMD}=0.40 ; 95 \% \text { CI }[0.30,0.51] ; \boldsymbol{p}<\mathbf{0 . 0 0 1}) \\
\text { Sub elite } \\
0-5 \mathrm{~m}(n=17 ; \mathrm{SMD}=1.09 ; 95 \% \text { CI }[0.72,1.47] ; \boldsymbol{p}<\mathbf{0 . 0 0 1}) \\
0-10 \mathrm{~m}(n=32 ; \mathrm{SMD}=0.69 ; 95 \% \text { CI }[0.51,0.86] ; \boldsymbol{p}<\mathbf{0 . 0 0 1}) \\
0-20 \mathrm{~m}(n=31 ; \mathrm{SMD}=0.63 ; 95 \% \text { CI }[0.40,0.86] ; \boldsymbol{p}<\mathbf{0 . 0 0 1})\end{array}$ \\
\hline Age & $\begin{array}{l}\mathbf{0 - 5} \mathbf{~ m} \\
\text { Senior vs youth } p=0.06 \\
\mathbf{0 - 1 0} \mathbf{~ m} \\
\text { Senior vs youth } \boldsymbol{p}=\mathbf{0 . 0 2} \\
\mathbf{0 - 2 0} \mathbf{~ m} \\
\text { Senior vs youth } \boldsymbol{p}<\mathbf{0 . 0 0 1}\end{array}$ & $\begin{array}{l}\text { Senior } \\
0-5 \mathrm{~m}(n=52 ; \mathrm{SMD}=0.82 ; 95 \% \text { CI }[0.62,1.03] ; \boldsymbol{p}<\mathbf{0 . 0 0 1}) \\
0-10 \mathrm{~m}(n=98 ; \mathrm{SMD}=0.66 ; 95 \% \text { CI }[0.53,0.79] ; \boldsymbol{p}<\mathbf{0 . 0 0 1}) \\
0-20 \mathrm{~m}(n=79 ; \mathrm{SMD}=0.60 ; 95 \% \text { CI }[0.45,0.75] ; \boldsymbol{p}<\mathbf{0 . 0 0 1}) \\
\text { Youth } \\
0-5 \mathrm{~m}(n=24 ; \mathrm{SMD}=0.51 ; 95 \% \text { CI }[0.26,0.77] ; \boldsymbol{p}<\mathbf{0 . 0 0 1}) \\
0-10 \mathrm{~m}(n=49 ; \mathrm{SMD}=0.42 ; 95 \% \text { CI }[0.27,0.58] ; \boldsymbol{p}<\mathbf{0 . 0 0 1}) \\
0-20 \mathrm{~m}(n=80 ; \mathrm{SMD}=0.30 ; 95 \% \text { CI }[0.20,0.39] ; \boldsymbol{p}<\mathbf{0 . 0 0 1})\end{array}$ \\
\hline
\end{tabular}


Table 5 (continued)

\begin{tabular}{|c|c|c|}
\hline Moderator variable & Between group differences & Subgroup standardised mean difference \\
\hline Phase & $\begin{array}{l}\mathbf{0 - 5} \mathbf{~} \\
\text { In-season vs off-season } \boldsymbol{p}=\mathbf{0 . 0 1} \\
\text { In-season vs pre-season } p=0.85 \\
\text { Pre-season vs off-season } \boldsymbol{p}=\mathbf{0 . 0 1} \\
\mathbf{0 - 1 0 ~} \mathbf{m} \\
\text { In-season vs off-season } p=0.26 \\
\text { In-season vs pre-season } p=0.60 \\
\text { Pre-season vs off-season } p=0.32 \\
\mathbf{0 - 2 0 ~} \mathbf{m} \\
\text { In-season vs off-season } \boldsymbol{p}=\mathbf{0 . 0 3} \\
\text { In-season vs pre-season } p=0.88 \\
\text { Pre-season vs off-season } \boldsymbol{p}=\mathbf{0 . 0 3}\end{array}$ & $\begin{array}{l}\text { In-season } \\
0-5 \mathrm{~m}(n=44 ; \mathrm{SMD}=0.78 ; 95 \% \text { CI }[0.59,0.96] ; \boldsymbol{p}<\mathbf{0 . 0 0 1}) \\
0-10 \mathrm{~m}(n=77 ; \mathrm{SMD}=0.60 ; 95 \% \text { CI }[0.48,0.73] ; \boldsymbol{p}<\mathbf{0 . 0 0 1}) \\
0-20 \mathrm{~m}(n=75 ; \mathrm{SMD}=0.41 ; 95 \% \text { CI }[0.29,0.53] ; \boldsymbol{p}<\mathbf{0 . 0 0 1}) \\
\text { Off-season } \\
0-5 \mathrm{~m}(n=3 ; \mathrm{SMD}=-0.16 ; 95 \% \text { CI }[-0.83,0.51] ; p=0.64) \\
0-10 \mathrm{~m}(n=3 ; \mathrm{SMD}=0.01 ; 95 \% \text { CI }[-1.02,1.04] p=0.99) \\
0-20 \mathrm{~m}(n=3 ; \mathrm{SMD}=-0.18 ; 95 \% \text { CI }[-0.7,0.34] ; p=0.50) \\
\text { Pre-season } \\
0-5 \mathrm{~m}(n=25 ; \mathrm{SMD}=0.78 ; 95 \% \text { CI }[0.45,1.11] ; \boldsymbol{p}<\mathbf{0 . 0 0 1}) \\
0-10 \mathrm{~m}(n=54 ; \mathrm{SMD}=0.54 ; 95 \% \text { CI }[0.35,0.73] ; \boldsymbol{p}<\mathbf{0 . 0 0 1}) \\
0-20 \mathrm{~m}(n=54 ; \mathrm{SMD}=0.42 ; 95 \% \text { CI }[0.26,0.59] ; \boldsymbol{p}<\mathbf{0 . 0 0 1})\end{array}$ \\
\hline
\end{tabular}

Subgroup analyses were performed on SMD between post and pre-intervention sprint performance outcome. Some studies were not included because the value used for subgroup analysis was not reported or did not match the appropriate categories

Bold font $=p<0.05$

N/A data not available, SMD standardised mean differences and $C I$ confidence interval

${ }^{a}$ Less than three studies in this training group

athletes over time show that mean annual within-athlete performance differences $(0.1-0.2 \%)$ are lower than typical variation, or smallest worthwhile change and the influence of external conditions (e.g., wind, temperature, altitude, timing methods/procedures) [37, 201]. Furthermore, an inspection of the funnel plot and Egger's regression intercept identified evidence of small-study effects for all performance outcomes. SMD between pre- and post-intervention short-sprint outcomes were not considered symmetrical, suggesting the presence of significant publication bias. While publication bias towards studies reporting positive outcomes may be involved, another plausible explanation is the lack of a control group in many studies, as the results might have been affected by learning effects or the football code training in the intervention period.

\subsection{Subgroup Analyses of Training Methods}

Training intervention subgroups (i.e., sport only, primary, secondary, tertiary, combined and combined-specific) were categorised based on the principle of specificity. Primary methods were the most specific to simulating the sprint movement pattern [202], and secondary methods were less specific as they overloaded the sprinting action. The tertiary training methods included strength, power and plyometric training and were, therefore, considered the least 'specific' to short-sprint performance. Instead of simulating the movement, these methods are commonly performed to target neuromuscular adaptations associated with increased hip, knee and ankle joint movements and the resultant magnitude of ground reaction forces generated during sprinting [203]. The extent to which the method impacts and 'transfers' to short-sprint performance ultimately determines the quality of a training programme and the exercises in the context of improving athletic performance [204].

The magnitude and orientation of ground reaction forces are the largest determinants of maximal running speed in humans [205-211]. Short-sprint performance is underpinned by an athlete's ability to generate the largest net horizontal force possible, averaged across each step [209, 212]. Therefore, the mechanical pretence of the included methodologies, work based on increasing impulse (net forces applied over time) and mechanical efficacy (forces applied in a horizontal direction as velocity increases) [212]. Effective training methods improve either or both the athletes' capacity to generate high levels of force relative to their body mass, while progressively reducing the contact time of each step and the mechanical effectiveness to transmit the force to the ground at progressively greater running velocities [205, 207, 209, 211, 213-215]. These improvements have been described to manifest in specific transferable training adaptations typically categorised as neural or morphological (architectural or structural) factors [216, 217]. Examples of neural adaptations are increased neural drive and activation, increased motor unit recruitment, increased rate coding and improved intra-muscular coordination (e.g., diversification of sensorimotor solutions; reduced antagonistic activation, increased synergistic activation and stiffness in highly similar patterns of recruitment to the target task [26, 212, 216-218]). Morphological adaptations can be categorised as either architectural adaptations (e.g., increased cross-sectional area, changes in pennation angle, fascicle length and stiffness [tendon and passive elements] $[26,195,212,216-218]$ ) or structural adaptations (e.g., fibre 
type transitions, the collagen content of extracellular matrix and the shift in expression of myosin heavy chain isoforms [26, 212, 216-218]). Practitioners exercise selection is typically based upon the principle of specificity, with a greater training transfer between the mechanical and physiological characteristics of the resistance training exercises and those of the performance movements enhancing the transfer of adaptations [21, 26, 44, 217]. Therefore, practitioners should also consider the shifting mechanical and neuromuscular (e.g., hip, knee, ankle flexors and extensors) requirements the change across the sub-phases (early-, mid- and late acceleration) of a short-sprint [26, 219-221].

\subsubsection{Sport Only Training}

Sport only training is the inclusion of football code training separate of any specific or non-specific sprint training; often undertaken to develop technical and tactical performance within football.

Sport only training (64 studies across football code athletes) was insufficient to significantly improve short-sprint performance at any distance $[42,66,73,74,79-81,83$, 85, 86, 88-92, 94, 97, 100, 101, 103, 106, 108, 112, 117, 125-128, 131, 132, 137, 139, 140, 142-152, 155-161, 165, $166,168,170,171,174,178,180]$. However, there was no negative effect on short-sprint performance. Although the movement demands of training are typically below game demands, the football codes are characterised by multidirectional and intermittent bouts of high-intensity running and sprinting interspersed between bouts of moderate and low-intensity activity (e.g., jogging, walking and repositioning [222-225]). Although during training and match play football code athletes repeatedly perform short-sprints (e.g., 5-20 m, 2-3 s) during and in between sport-specific actions $[12,222,223,226,227]$ athletes are exposed to limited or no very high-speed or sprint threshold running [224, 225, 228] and incomplete rests between sprints. Recommendations for improving sprint performance state that sprints should be at 95-100\% max effort with complete recovery [201]. Research has demonstrated that residual fatigue reduces an athlete's ability to generate force-power-velocity and mechanical efficacy during games and in response, incomplete recovery between sprints [229, 230]. Given the exponential relationship between power and velocity, a reduction from the maximal intensity of the short-sprints would represent a substantial reduction in force and power load on the neuromuscular system providing an insufficient stimulus for adaptation [201]. At a biochemical level, the sport only training movement demands presents a conflicting stimulus, potentially eliciting an interference effect on the development of maximal force and power [231]. The interference effect will then likely affect the resultant magnitude of ground reaction forces the athlete can generate, preventing an athlete from developing short-sprint performance [231]. Therefore, evidence suggests that sport only training alone is insufficient to improve short-sprint performance outcomes. Practitioners should be aware of this within their planning and delivery of training within football code athletes.

\subsubsection{Primary Methods}

Primary methods $(n=8)$ simulate the sprint movement pattern (e.g., sprint-technique drills, stride length and frequency exercises and sprints of varying distances and intensities). The current findings suggest that primary training methods $[66,79,89,106,134,135,155,177]$ may not significantly improve short-sprint performance, and in some cases, may impair performance. The primary methods training groups presented no significant change in short-sprint performance (i.e., $0-5 \mathrm{~m} \mathrm{SMD}=-0.13$ [95\% CI - 0.39, 0.13], 0-10 m $\mathrm{SMD}=-0.04[95 \% \mathrm{CI}-0.40,0.33], 0-20 \mathrm{~m} \mathrm{SMD}=0.05$ $[95 \% \mathrm{CI}-0.08,0.18])$. The results of the primary training subgroup showed no significant improvement in shortsprint performance, contrasting with previous findings and the principle of specificity [43, 48]. This contradiction in findings with previous reviews $[43,48]$ suggests misclassification of the training methods used previously as these studies failed to include the additional training (e.g., resistance training) completed by the athletes, most probably as part of their usual training (e.g., [42, 105, 114-116, 176]). Therefore, previous review findings may support a combined approach of both specific and nonspecific training, not primary training alone [43, 48].

Maximal sprinting exposes the neuromuscular system to large forces ( $>2 \times$ bodyweight) produced during short ground contact periods $(\sim 0.080-0.200 \mathrm{~s})$ performed at high movement velocities $\left(7-10 \mathrm{~m} \cdot \mathrm{s}^{-1}\right)$ resulting in both a coordinative overload and high neuromuscular stimulation [205, 207-209, 211, 232, 233]. The exposure to sprinting maximally, therefore, is expected to facilitate chronic physical and technical adaptations to improve short-sprint performance [204, 205, 207-209, 211, 232]. However, previous research in football code athletes reported that primary training methods showed no significant increase in stride length and a significant reduction in stride frequency despite a non-significant increase in sprint performance [155]. This is likely due to the included athlete population's high chronic exposure to short-sprints with incomplete recovery as part of the demands of training and matches resulting in insufficient stimulus for neurological or morphological adaptations [222-225, 234]. Training guidelines for improving shortsprint performance recommend between $10-50 \mathrm{~m}$ sprints at $>98 \%$ maximal intensity with full recovery $\left(1-2 \mathrm{~min} \cdot \mathrm{s}^{-1}\right.$ of activity) between each sprint, to prevent a drop-off in performance [201]. However, most of the studies in this systematic review provide short incomplete rest periods 
between repetitions (e.g., 1-3 min between repetitions) for 20-30 m sprints (3-4 to 4-5 s). Incomplete rest between sprints results in metabolic stress and exhaustion of energy substrate which may reduce the maximal sprint intensity by several mechanisms (e.g., weakened actin-myosin crossbridges, reduction in the efficacy of signal transmission in the neuromuscular junction and alterations in neuromuscular activation [235-237]). Therefore, reducing the force and power load on the neuromuscular system when sprinting, reducing or preventing positive adaptations [106]. Longer training adaptation kinetics should also be considered, as the performance changes may have been affected by residual fatigue delaying the expression of an improved of performance output until after the testing incidence [201, 234, 238]. Therefore, primary training methods with short rests between sprints intervals is insufficient to improve shortsprint performance outcomes. Future studies should provide complete rest periods between maximal intensity sprints and test performance changes more frequently.

Technique drills are a component of the primary training subgroup. Technique drills simulate the sprinting action by isolating specific movements into more manageable components [201, 239]. For positive reinforcement of the technique to occur, the sprinting biomechanics must closely resemble the action and develop the athlete's limiting factor [202, 240]. However, technique drills (e.g., A and B drills) are performed at much slower velocities than sprinting, and, therefore, they do not replicate sprinting from a kinematic standpoint [241]. Therefore, researchers have suggested that they have limited value, particularly when performed poorly, and they artificially constrain a sprinter's technique [242, 243]. Although coaches [16] and training studies [104, 131] have included sprint technique drills in their training prescription, currently no studies in football code athletes have identified the training effects of inclusion and exclusion of running technique drills. When studies have included running drills, there is a limited explanation of the training prescription applied. Therefore, it may be more appropriate for technical speed training to address improvements in the magnitude and rate of force production on the ground and the mechanical efficiency (e.g., tertiary or secondary methods) [243]. Future studies should devote more attention to the effectiveness of sprint mechanics drills.

\subsubsection{Secondary Methods}

Secondary training modalities apply overload to the sprinting action by reducing (e.g., resisted sprinting) or increasing the movement speed allowing athletes to reach supramaximal velocities (e.g., assisted sprinting). Across the five studies, findings showed significant moderate improvements for all short-sprint performance outcomes $(0-5 \mathrm{~m} \mathrm{SMD}=0.75$ [95\% CI 0.07, 1.43], 0-10 m SMD $=0.52$ [95\% CI 0.11,
0.93] and 0-20 m SMD $=0.64$ [95\% CI 0.05, 122]). Training adaptations are reported to be velocity change $\left(\% V_{\max }\right.$ increase vs reduction) specific [212, 244], with different significant distance specific improvements reported for secondary methods (i.e., assisted vs. resisted) [173]. The overload of the secondary training methods results in neurological or morphological adaptations allowing greater generation of ground reaction forces and improved mechanical efficiency to enhance short sprint performance [48, 52]. Resisted sprints have been shown to increase stride length and forward trunk lean (improved position to generate horizontal impulse) in track athletes [48, 52]. Whereas assisted methods have demonstrated increases in stride length and decreased stride frequency in track athletes [48, 52]. There are currently no studies measuring chronic kinematic changes in response to secondary training methods (no additional tertiary methods training) to support these in football code athletes. Of the two overload strategies, resisted sprint training $[77,79,87,89,192]$ has received the greatest attention in the research in football code athletes despite significant improvements in both training methods (resisted [79, 89] and assisted [173]). Currently, no study has reported a statistically superior training effect between assisted and resisted training modes. Hence, it is unclear which training mode is the most effective for developing short-sprint performance. Therefore, secondary training methods are an effective method for coaches and athletes to improve short sprint performance outcomes. Further research is required to determine the optimal load and dose for performance enhancement.

\subsubsection{Combined Specific Methods}

Combined specific methods are a combination of both primary and secondary methods (e.g., sprinting and resisted sprinting). No previous review study has included combined specific training as a training method within their analysis, potentially due to the limited studies $(n=3)$ that have evaluated the effectiveness of such training methods [127, $128,134]$. Current findings showed significant moderate improvements in 0-5 $\mathrm{m}$ performance $(\mathrm{SMD}=0.54$ [95\% CI $0.02,1.07])$ and large improvements in $0-10 \mathrm{~m}$ performance (SMD $=0.96[95 \%$ CI $0.59,1.33]$ ) with small but no significant improvements at 0-20 m (SMD 0.32 [95\% CI $-0.08,0.72])$. Improvements in short-sprint performance may occur from the enhancement of physical qualities (e.g., $\left.F_{0}, V_{0}, P_{\max }\right)[134]$ and mechanical improvements (increased stride length and frequency). For example, research has identified that ordering resisted sled pushing/pulling before unresisted sprint training can potentiate subsequent sprint performance $[245,246]$. Therefore, increasing the neuromuscular stimulus, hence providing the necessary overload for this population to produce favourable neurological and or 
morphological adaptations. Such findings suggest that combined specific training methods may be an effective method for coaches and athletes to improve short-sprint performance outcomes; however, further research is warranted to support its effectiveness.

\subsubsection{Tertiary Methods}

Tertiary training methods are the most common within the research evidence base $(n=74)$ representing a wide range of training methods (e.g., strength, power, plyometrics [43, 247]). Although these training forms do not replicate the sprint running movement, they provide targeted stimuli to the underpinning mechanical components of the neuromuscular system that determine short-sprint performance (e.g., force-velocity-power and force-velocity profile) $[26,201$, 212, 219].

The load velocity relationship enables practitioners to prescribe the appropriate resistance (bodyweight or external loads) of tertiary training methods to limit either or both the maximum velocity and force at which the maximum effort will occur [248]. This enables practitioners to target load specific adaptations using force-velocity-power orientated exercises in isolation or in combination (e.g., high-force/ low-velocity vs low-force/ high-velocity vs peak power load) [26, 201, 212, 219].

Despite previous criticisms in the literature questioning the effectiveness for developing sprint performance (e.g., the duration available to apply force, no rotation-extension strategy, lack impact-limb deceleration mechanism [26]), significant moderate improvements were found for all short-sprint performance outcomes $(0-5 \mathrm{~m} \mathrm{SMD}=0.64$ [95\% CI 0.42, 0.86], 0-10 m SMD =0.56 [95\% CI 0.42, 0.70], 0-20 m $\mathrm{SMD}=0.40$ [95\% CI 0.30, 0.51]). Research comparing the kinetic factors underlying accelerative performance found that sprinters achieve higher maximum velocities compared to soccer athletes by attenuating the eccentric forces to a greater extent in the late braking phase and producing a higher antero-posterior component of force across almost the entire propulsive phase [34]. Therefore, training methods that increase an athlete's ability to produce sufficient vertical force, to withstand and reverse eccentric braking forces and to generate high antero-posterior propulsive force are required, such as strength, power or plyometrics training $[34,201]$. The improved physical qualities developed during tertiary training methods have been shown to manifest in significant improvements in short-sprint performance with associated reductions in stride frequency and increases in stride length $[114,116]$. These findings present that high correspondence exists between the larger propulsive forces produced within the first few steps of short-sprints and the neural and morphological adaptations induced by these training methods [211].
Although performance increases are attributed to neurological or morphological adaptations from tertiary training methods, the morphological adaptations to these methods are often associated with increases in muscle cross-sectional area, such as non-uniform regional hypertrophy of both the hip and thigh enabling greater force production capabilities advantageous for accelerating hip extension and producing greater propulsive forces [249-251]. Considerations should be made when training for increased mass development as an athlete gets heavier; they may not produce higher maximal force characteristics $\left(F_{0}\right)$ when normalised for body mass [203]. The force requirements to accelerate their body mass also increases, as does the aerodynamic drag resulting from a wider frontal surface area [203, 252]. Hence, chasing increases in body mass may be counterproductive for sprinting, at least when not moving an external mass [203]. Therefore, the results of the meta-analyses support Rumpf's [43] previous findings, that tertiary training methods performed individually or in combination (e.g., strength power and plyometrics training) are an effective method for enhancing sprint performance. Rumpf's lower sample of studies ( $n=18-21$ vs. $n=54-56)$ would have resulted in a greater sensitivity to larger negative training responses, therefore, explaining the lower reported training effects (effect size $=0.3-0.35$ for $0-10$ and $0-20 \mathrm{~m}$ respectively).

\subsubsection{Combined Methods}

Combined methods training includes both specific sprint training (primary and or secondary methods) and tertiary methods. Researchers, elite coaches, track and field sprinting coaches and team sports strength and conditioning coaches have suggested utilising an integrated approach utilising a combination of specific and non-specific methods is likely to be the most effective way to develop speed $[16,43,204$, 217, 253-255]. Elite coaches suggest a combined training approach using non-specific strength training or developing "gym strength" (e.g., heavy back squats) in conjunction with resisted sport-specific actions (e.g., resisted sprinting with sleds) would increase the chances of positive transfer [256]. This combination of both methods enables practitioners to provide stimuli to develop both the physical qualities of the lower limb and the mechanical efficiency concurrently [114, 116, 131, 182]. Previous studies, combining specific and tertiary training methods, demonstrated significant improvements in physical qualities [131], stride length and stride frequency $[114,116]$. Current findings demonstrated that combined training methods $(n=49)$ were an effective method of developing short-sprint performance producing significant moderate-large SMD at 0-5 m (SMD 0.92 [95\% CI $0.66,1.18$ ]), 0-10 m (SMD 0.60 [95\% CI 0.44, 0.75]) and 0-20 m (SMD 0.56 [95\% CI 0.39, 0.74]). Despite presenting the greatest training effects, each method presented 
different training methods (e.g., Electronic Supplementary Material Table S3). Therefore, combined specific methods are an effective training method for football code athletes and provide multiple options for practitioners and athletes to develop short-sprint performance. However, further research is required to identify the optimal combination of exercises and training loads to improve short-sprint performance.

\subsection{Moderator Variables}

It is important to identify the moderator variables (i.e., football code, sex, age, playing standard, stage of the season) that may impact upon short-sprint training outcome [62]. Studies were not included in the analysis if the value used for subgroup analysis was not reported, failed to provide sufficient detail or did not match the appropriate moderator categories.

\subsubsection{Sex}

The meta-analysis of the intervention training groups found that both male and female football code athletes' short-sprint performance can be improved. When comparing male and female athletes, there was no significant difference between the training effects. This should be taken within the context of the scarcity of the available information with female athletes training compared to males. No study was included that has compared the difference between training outcome by sex implementing matched training interventions in football code athletes. Therefore, despite the demonstrated differences between physical characteristics [4, 203] and endocrine response [257] to training between males and females, there is currently no sufficient evidence to suggest practitioners should approach developing short-sprint performance differently based on an athlete's sex.

\subsubsection{Playing Standard}

Both elite and sub-elite cohort subgroups short-sprint performance was improved across all short-sprint outcomes. The between-group comparison identified the sub-elite populations had a significantly greater training effect than the elite populations at $0-5 \mathrm{~m}$. There was no significant difference between the training effects for $0-10 \mathrm{~m}$ and $0-20 \mathrm{~m}$. Previous research has identified that amateur players report larger benefits to specific training methods programs than elite athletes [258-260]. This is interesting considering research has demonstrated that lower performance standard populations, have large correlations between vertical and horizontal force-velocity-power variables [200]. Vertical profiles have been suggested to reflect the lower limbs neuromuscular maximal capabilities [200, 219]. This suggests that the ability to develop horizontal force during sprinting is associated with the ability of the lower limbs to develop force [200, 219]. Jiménez-Reyes [200] suggested that by training force and power production capabilities (e.g., strength and power training), it could effectively improve sprinting performance. However, in high playing standard populations (elite), horizontal force production during sprinting acceleration has a weaker association and is less determined by the maximal capabilities of the neuromuscular system to produce force. Therefore, further improvements may be represented by the ability to effectively apply horizontal force into the ground at progressively increasing velocities (mechanical effectiveness). Hence a greater focus on developing mechanical efficiency may be required (e.g., very heavy resisted sled sprints [134]). However, further research is required to discriminate between playing standards if there are mode-specific differences. Therefore, despite the demonstrated differences between physical characteristics between elite and sub-elite athletes [203] when considered independent of training status there is insufficient evidence to suggest practitioners should approach developing short sprint performance differently based on athlete's playing standard within the football codes.

\subsubsection{Age}

Both senior and youth cohort subgroups short-sprint performance was enhanced following training interventions. However, between-group comparisons identified senior athletes enhanced short-sprint performance more than youth athletes at $0-10 \mathrm{~m}$ and $0-20 \mathrm{~m}$. This finding is surprising with previous research showing that younger athletes typically have a greater training response compared to older counterparts [45, 157, 174]. Factors such as maturation may have moderated the training effects of the primary sprint training methods in male youth athletes with a greater training effect in pre- vs. mid-peak height velocity and early and late stage of maturation $[45,174]$. This is supported by the finding that between age differences were found for sprint performance changes in younger athletes. These training effects suggest that within youth athlete cohorts, coaches should take into consideration, including chronological age, maturation, as well as the associated increase baseline performance levels and greater training experience [157]. However, further research is required to understand short-sprint performance outcomes by age, which could include maturity grouping.

\subsubsection{Sport}

Short-sprint performance was improved in soccer, futsal $[113,159,171]$ and rugby union $[103,129,175,176]$ but not for rugby league $[71,72,84,93,104]$ or rugby sevens $[75,182]$ in the $0-10 \mathrm{~m}$ distance outcome. Several football codes training subgroups had only 1-2 training groups due 
to limited representation in the literature for a given distance outcome (0-5 m Rugby league [ $n=1$ ] [84], $0-10 \mathrm{~m}$ and 0-20 m Australian rules football $[n=2]$ [162] and 0-20 m Futsal $[n=2]$ [171]). Therefore, these subgroup analyses were not considered. Despite the differences in physical characteristics [200, 203] and movement demands [222, 223 ] in the football codes, the only significant betweensubgroup difference was in the $0-10 \mathrm{~m}$ performance outcome. The between-group comparison showed rugby sevens had a significantly lower change in performance than soccer, rugby union and futsal presenting a non-significant reduction in sprint performance. Although the data shows there are differences between football code subgroups, there is insufficient literature to demonstrate this consistently across all short sprint distance outcomes, and it is currently unclear whether these are specific to training methods or distance outcomes. No study was included that has compared the difference between training effects between football codes implementing matched training interventions in football code athletes on short-sprint performance. Therefore, despite the differences in physical characteristics presented between football codes, there is insufficient evidence to support coaches adapting short-sprint training methods based on football code.

\subsubsection{Season}

Both pre-season and in-season subgroups, short-sprint performance was improved, despite the typical reductions in the time available for practitioners to develop physical or movement qualities during the in-season period [47]. The off-season subgroup [64, 85, 136] presented no significant improvement. It is generally reported that fitness improvements are observed in the preseason, with a subsequent stabilisation of such fitness variables in-season [261]. Consequently, higher benefits are expected in trials performed during the preseason period compared with in-season [179, 259]. Therefore, if prescribed appropriately, there appears to be no significant difference of season between the training effects in football code athletes. The between-group comparison identified that both pre-season and in-season produced significantly larger improvements than off-season training in all performance outcomes. This has likely been skewed as a result of the large significant reduction in sprint performance observed in the study by Nakamura [136] due to the inclusion of only three training groups per outcome. No study was included that has compared the difference between training effects between the phase of the season implementing matched training interventions in football code athletes on short-sprint performance. Therefore, despite the differences in training demands between training phases, there is insufficient evidence to support coaches adapting short-sprint training methods based on the phase of the season.

\subsection{Limitations}

This study represents the largest systematic review and metaanalysis of short-sprint performance development methods and the only to exclusively assess within and across football code athletes, but it is not without limitations. Firstly, this review classified training into training method groups (i.e., sport-only, primary, secondary, tertiary, combined and combined specific). While this improves on previous classifications [43, 44], it also fails to consider the complexity of short-sprint performance development considering training prescription, combined with the population and assessment methodologies. Therefore, the level of detail to fully understand short-sprint development is lacking, but this is difficult in the context of understanding sprint development and the multiple factors that interact. However, while we tried to consider numerous moderator variables (i.e., football code, sex, playing standard, age and phase of the season), this highlighted a further limitation of the existing research base in that research is mainly undertaken using parallel groups trials within male soccer athletes involving mainly tertiary training methods. Therefore, research including randomised control trials across the football codes, female cohorts, which utilise specific training methods are limited, which may impact the meta-analysis and moderator variable analysis and subsequent interpretation.

Sensitivity analysis of the data set revealed minor changes only, for the majority of performance variables, and these changes did not substantially impact the overall mean effect. However, the removal of the Mathisen and Danielsen [127] from the limited number of combined specific training subgroup moderated the statistical interpretation of the results. Although removing one or more studies independently did not affect the statistical significance of the tertiary methods the study by Asadi [74] should be scrutinised presenting an extreme performance improvement of 1.03 s (36.79\%) in mean $20 \mathrm{~m}$ sprint performance. No other performance outcome improved by over $0.40 \mathrm{~s}(11.8 \%)$ [139]. While the limitations above exist, the information gathered from the current review with meta-analysis may support practitioners to use evidence-informed decisions when organising and evaluating training and generating future research.

\subsection{Future Research Directions}

Future research investigating short-sprint performance development should be performed using high study quality designs (e.g., randomised control trials) examining the training effects in football codes outside of soccer (e.g., rugby codes, American, Australian rules, Gaelic football and futsal), world-class and successful elite athletes, trained populations with systematic training exposures and within female athlete cohorts. It should also be considered pairing subjects based on physical 
characteristics to establish a better understanding of whether training changes and adaptations are dependent upon resistance training experience and/or physical characteristics of the athlete. Future studies should consider modelling athlete's velocity-time curve to reduce the limitations associated with pre and post sprint times or velocities [61]. This method would allow a better comparison between studies (improving future meta-analyses) while allowing practitioners to identify the mechanical profile of the athlete [262]. Combined modelling of velocity-time curves with the assessment of kinematic and kinetic changes performed at more frequent intervals would enable practitioners to isolate and confirm a time course of adaptations and the underlying causes to changes in performance $[4,200,219]$. A more comprehensive overview of developing football code athletes sprinting performance may be achieved by future research exploring the effectiveness of non-linear sprint interventions including change of directions variations (e.g., swerve running, $180^{\circ}$ turns) as well as reviewing the development of RSA, nonlinear and sprint outcomes $>20 \mathrm{~m}$, due to their respective importance in the football codes.

Research has identified researchers, elite coaches, track and field sprinting coaches and team sport strength and conditioning coaches have suggested utilising an integrated approach utilising a combination of specific and nonspecific training performed individually in separate sessions or combinations (e.g., complex or contrast sets) to develop multiple physical qualities and skills simultaneously $[16,43,204,217$, 253-255]. Therefore, further research would be better suited to manipulating the combinations, sequencing and loading parameters of combined specific and non-specific methods to enhance sprint performance longitudinally. This should be combined with methods of the profiling that allow optimisation and individualisation of training exposures [219, 247, 262-264]. This may reduce the variability in performance change [247]. While exercise specificity is certainly an important principle when developing a training program, it is only one of several principles that will influence the effectiveness of the program. Therefore, future research should continue to explore within and between-subgroups the effects of overload, variation, reversibility and the effect on sprint performance change [26]. Furthermore, this needs to be supported with determining the minimal and optimal training doses to retain and develop short-sprint performance in football code athletes. This will directly influence practitioner's organisation of training and the prescribed loading variables.

\section{Conclusions}

Short-sprint performance is an important attribute for football code athletes. Hence, establishing the most effective methods to improve performance is an important consideration for practitioners working across the football codes. This review provides the largest systematic review and meta-analysis comparing multiple training methods for developing short-sprint performance within football code athletes. An athlete's short-sprint performance is underpinned by their physical qualities (force-velocity-power) and mechanical effectiveness, thus providing practitioners with multiple methods of developing this quality. The included cohort of football code athletes (limited systematic exposure to the specific and nonspecific training stimulus) enhanced short-sprint performance $(0-5,0-10 \mathrm{~m}, 0-20 \mathrm{~m})$ through secondary (i.e., resisted or assisted sprinting), tertiary (i.e., strength, power and plyometrics) and combined (i.e., primary or secondary and tertiary training methods) training modes. Combined specific training methods (i.e., primary and secondary methods) also improved shortsprint performance $(0-5$ and $0-10 \mathrm{~m})$. However, based on this training mode alone, there is yet to be a presented most effective method. Both sport only training and primary training methods (i.e., sprinting, running drills) are insufficient to develop short-sprint performance. Moderator effects, although not mode-specific, suggest that there is not a consistent effect of age, sex, playing standard and phase of the season on short-sprint performance change. Regardless of the population characteristics, short-sprint performance can be enhanced by increasing either or both the magnitude and the orientation of force an athlete can generate and express in the sprinting action. These findings present practitioners with several options to suit their programme to enhance short-sprint performance, but future research needs to consider the interactions between training methodologies and applied practice to understand the impact of training on short-print performance fully. In conclusion, further high-quality research is warranted to confirm and possibly extend the results of this systematic meta-analytical review. Future studies should devote more attention to optimising and individualising training to maximise the training response; as well as the limited research into female cohorts, football code athletes outside of soccer, specific training methodologies.

\section{Declarations}

Funding No sources of funding were used to assist in the preparation of this article.

Conflict of interest Ben Nicholson, Alex Dinsdale, Ben Jones and Kevin Till declare no potential conflicts of interest concerning the research, content, authorship and/or publication of this review.

Ethics approval Approval was obtained from the ethics committee of Leeds Beckett University. The procedures used in this study comply with the ethical standards of the Declaration of Helsinki.

Consent to participate Not applicable. 
Consent for publication Not applicable.

Availability of data and materials The datasets generated during and/or analysed during the current study are available from the corresponding author on reasonable request.

\section{Code availability Not applicable.}

Author contributions All the authors contributed to the manuscript, including the conception and design of the study, analysis and interpretation of the data, drafting and critically revising the manuscript, and approval for publication. All authors read and approved the final manuscript.

Open Access This article is licensed under a Creative Commons Attribution 4.0 International License, which permits use, sharing, adaptation, distribution and reproduction in any medium or format, as long as you give appropriate credit to the original author(s) and the source, provide a link to the Creative Commons licence, and indicate if changes were made. The images or other third party material in this article are included in the article's Creative Commons licence, unless indicated otherwise in a credit line to the material. If material is not included in the article's Creative Commons licence and your intended use is not permitted by statutory regulation or exceeds the permitted use, you will need to obtain permission directly from the copyright holder. To view a copy of this licence, visit http://creativecommons.org/licenses/by/4.0/.

\section{References}

1. Bishop DJ, Girard O. Determinants of team-sport performance: implications for altitude training by team-sport athletes. $\mathrm{Br} \mathbf{J}$ Sports Med. 2013;47:i17-21.

2. Till K, Scantlebury S, Jones B. Anthropometric and physical qualities of elite male youth rugby league players. Sports Med. 2017;47(11):2171-86.

3. Delaney JA, Olson TM, Morin J-B. Sprint acceleration mechanical profiling for the NFL draft. Sports Perform Sci Rep. 2018;27.

4. Baumgart C, Freiwald J, Hoppe M. Sprint mechanical properties of female and different aged male top-level German soccer players. Sports. 2018;6(4):161.

5. Al Haddad H, Simpson BM, Buchheit M, Di Salvo V, MendezVillanueva A. Peak match speed and maximal sprinting speed in young soccer players: effect of age and playing position. Int $\mathrm{J}$ Sports Physiol Perform. 2015;10(7):888-96.

6. Gabbett TJ, Jenkins DG, Abernethy B. Relationships between physiological, anthropometric, and skill qualities and playing performance in professional rugby league players. J Sports Sci. 2011;29(15):1655-64.

7. Gabbett T, Kelly J, Pezet T. Relationship between physical fitness and playing ability in rugby league players. J Strength Cond Res. 2007;21(4):1126.

8. Young W, Pryor L. Relationship between pre-season anthropometric and fitness measures and indicators of playing performance in elite junior Australian rules football. J Sci Med Sport. 2007;10(2):110-8.

9. Smart D, Hopkins WG, Quarrie KL, Gill N. The relationship between physical fitness and game behaviours in rugby union players. Eur J Sports Sci. 2014;14:S8-17.

10. Cunningham DJ, Shearer DA, Drawer S, Pollard B, Cook CJ, Bennett M, et al. Relationships between physical qualities and key performance indicators during match-play in senior international rugby union players. PLoS ONE. 2018;13(9):e0202811.
11. Ross A, Gill N, Cronin J, Malcata R. The relationship between physical characteristics and match performance in rugby sevens. Eur J Sports Sci. 2015;15(6):565-71.

12. Faude O, Koch T, Meyer T. Straight sprinting is the most frequent action in goal situations in professional football. J Sports Sci. 2012;30(7):625-31.

13. Bishop D, Girard O, Mendez-Villanueva A. Repeated-sprint ability_-part II: recommendations for training. Sports Med. 2011;41(9):741-56.

14. Lockie RG, Moreno MR, Orjalo AJ, Stage AA, Liu TM, Birmingham-Babauta SA, et al. Repeated-sprint ability in Division I collegiate male soccer players: positional differences and relationships with performance tests. J Strength Cond Res. 2019;33(5):1362-70.

15. Ingebrigtsen $\mathrm{J}$, Brochmann $\mathrm{M}$, Castagna $\mathrm{C}$, Bradley $\mathrm{PS}$, Ade J, Krustrup P, et al. Relationships between field performance tests in high-level soccer players. J Strength Cond Res. 2014;28(4):942-9.

16. Jones TW, Smith A, Macnaughton LS, French DN. Strength and conditioning and concurrent training practices in elite rugby union. J Strength Cond Res. 2016;30(12):3354-66.

17. Brown TD, Vescovi JD, Vanheest JL. Assessment of linear sprinting performance: a theoretical paradigm. J Sports Sci Med. 2004;3(4):203-10.

18. Barr MJ, Sheppard JM, Newton RU. Sprinting kinematics of elite rugby players. J Aust Strength Cond. 2013;21(4):14-20.

19. Volkov N, Lapin V. Analysis of the velocity curve in sprint running. Med Sci Sports. 1979;11(4):332-7.

20. Mann R, Murphy A. The mechanics of sprinting and hurdling. Long Beach: Ralph V. Mann; 2015.

21. Buchheit M, Samozino P, Glynn JA, Michael BS, Al Haddad H, Mendez-Villanueva A, et al. Mechanical determinants of acceleration and maximal sprinting speed in highly trained young soccer players. J Sports Sci. 2014;32(20):1906-13.

22. Sleivert G, Taingahue M. The relationship between maximal jump-squat power and sprint acceleration in athletes. Eur J Appl Physiol. 2004;91(1):46-52.

23. Delecluse C, Coppenolle HV, Willems E, Diels R, Goris M, Leemputte MV, et al. Analysis of 100 meter sprint performance as a multi-dimensional skill. J Hum Mov Stud. 1995;28(2):87.

24. Jones R, Bezodis I, Thompson A. Coaching sprinting: expert coaches' perception of race phases and technical constructs. Int J Sports Sci Coach. 2009;4(3):385-96.

25. Bellon $\mathrm{C}$. The relationship between strength, power, and sprint acceleration in division I men's soccer players [Doctoral dissertation]: East Tennessee State University; 2016.

26. Moir GL, Brimmer SM, Snyder BW, Connaboy C, Lamont HS. Mechanical limitations to sprinting and biomechanical solutions: a constraints-led framework for the incorporation of resistance training to develop sprinting speed. Strength Cond J. 2018;40(1):47-67.

27. Mendez-Villanueva A, Buchheit M, Kuitunen S, Douglas A, Peltola ESA, Bourdon P. Age-related differences in acceleration, maximum running speed, and repeated-sprint performance in young soccer players. J Sports Sci. 2011;29(5):477-84.

28. Little T, Williams AG. Specificity of acceleration, maximum speed, and agility in professional soccer players. J Strength Cond Res. 2005;19(1):76-8.

29. Vescovi JD, Mcguigan MR. Relationships between sprinting, agility, and jump ability in female athletes. J Sports Sci. 2008;26(1):97-107.

30. Clark KP, Rieger RH, Bruno RF, Stearne DJ. The national football league combine 40-yd dash: how important is maximum velocity? J Strength Cond Res. 2019;33(6):1542-50. 
31. Nagahara R, Matsubayashi T, Matsuo A, Zushi K. Kinematics of transition during human accelerated sprinting. Biol Open. 2014;3(8):689-99.

32. Nagahara R, Naito H, Morin J-B, Zushi K. Association of acceleration with spatiotemporal variables in maximal sprinting. Int J Sports Med. 2014;35(09):755-61.

33. Wild JJ, Bezodis IN, North JS, Bezodis NE. Differences in step characteristics and linear kinematics between rugby players and sprinters during initial sprint acceleration. Eur J Sports Sci. 2018;18(10):1327-37.

34. Colyer SL, Nagahara R, Takai Y, Salo AI. How sprinters accelerate beyond the velocity plateau of soccer players: waveform analysis of ground reaction forces. Scand J Med Sci Sports. 2018;28(12):2527-35.

35. Sides D. Kinematics and kinetics of maximal velocity sprinting and specificity of training in elite athletes. Salford: University of Salford; 2015.

36. Bissas A, Walker J, Tucker C, Paradisis G, Merlino S. Biomechanical report for the IAAF world championships London 2017 Men's 100m. 2018.

37. Haugen T, Buchheit M. Sprint running performance monitoring: methodological and practical considerations. Sports Med. 2016;46(5):641-56.

38. Simperingham KD, Cronin JB, Ross A. Advances in sprint acceleration profiling for field-based team-sport athletes: utility, reliability, validity and limitations. Sports Med. 2016;46(11):1619-45.

39. García-Ramos A, Haff GG, Feriche B, Jaric S. Effects of different conditioning programmes on the performance of high-velocity soccer-related tasks: systematic review and meta-analysis of controlled trials. Int J Sports Sci Coach. 2018;13(1):129-51.

40. Douglas J, Pearson S, Ross A, McGuigan M. Effects of accentuated eccentric loading on muscle properties, strength, power, and speed in resistance-trained rugby players. J Strength Cond Res. 2018;32(10):2750-61.

41. Loturco I, Nakamura F, Kobal R, Gil S, Pivetti B, Pereira L, et al. Traditional periodization versus optimum training load applied to soccer players: effects on neuromuscular abilities. Int J Sports Med. 2016;37(13):1051-9.

42. Spinks CD, Murphy AJ, Spinks WL, Lockie RG. The effects of resisted sprint training on acceleration performance and kinematics in soccer, rugby union, and Australian football players. J Strength Cond Res. 2007;21(1):77-85.

43. Rumpf MC, Lockie RG, Cronin JB, Jalilvand F. Effect of different sprint training methods on sprint performance over various distances: a brief review. J Strength Cond Res. 2016;30(6):1767-85.

44. Plisk S. Speed, agility, and speed-endurance development. 2nd ed. Human Kinetics: Champaign; 2000. p. 471-91.

45. Moran J, Sandercock G, Rumpf MC, Parry DA. Variation in responses to sprint training in male youth athletes: a meta-analysis. Int J Sports Med. 2017;38(01):1-11.

46. Freitas TT, Martinez-Rodriguez A, Calleja-González J, Alcaraz PE. Short-term adaptations following complex training in teamsports: a meta-analysis. PLoS ONE. 2017;12(6):e0180223.

47. Haugen T. Sprint conditioning of elite soccer players: worth the effort or lets just buy faster players? Sport Perform Sci Rep. 2017;1:1-2

48. Alcaraz PE, Carlos-Vivas J, Oponjuru BO, Martínez-Rodríguez A. The effectiveness of resisted sled training (RST) for sprint performance: a systematic review and meta-analysis. Sports Med. 2018;48(9):2143-65

49. Ryan R. Heterogeneity and subgroup analyses in Cochrane Consumers and Communication Review Group reviews: planning the analysis at protocol stage. Cochrane Consumers Communication Review Group. 2014.
50. Bauer P, Uebellacker F, Mitter B, Aigner AJ, Hasenoehrl T, Ristl R, et al. Combining higher-load and lower-load resistance training exercises: a systematic review and meta-analysis of findings from complex training studies. J Sci Med Sport. 2019;22(7):838-51.

51. Moran JJ, Sandercock GR, Ramírez-Campillo R, Meylan CM, Collison JA, Parry DA. Age-related variation in male youth athletes' countermovement jump after plyometric training: a meta-analysis of controlled trials. J Strength Cond Res. 2017;31(2):552-65.

52. Petrakos G, Morin J-B, Egan B. Resisted sled sprint training to improve sprint performance: a systematic review. Sports Med. 2016;46(3):381-400.

53. Bolger R, Lyons M, Harrison AJ, Kenny IC. Sprinting performance and resistance-based training interventions: a systematic review. J Strength Cond Res. 2015;29(4):1146-56.

54. Hrysomallis $\mathrm{C}$. The effectiveness of resisted movement training on sprinting and jumping performance. J Strength Cond Res. 2012;26(1):299-306.

55. Harries SK, Lubans DR, Callister R. Resistance training to improve power and sports performance in adolescent athletes: a systematic review and meta-analysis. J Sci Med Sport. 2012;15(6):532-40.

56. Rumpf MC, Cronin JB, Pinder SD, Oliver J, Hughes M. Effect of different training methods on running sprint times in male youth. Pediatr Exerc Sci. 2012;24(2):170-86.

57. de Villarreal ES, Requena B, Cronin JB. The effects of plyometric training on sprint performance: a meta-analysis. J Strength Cond Res. 2012;26(2):575-84.

58. Liberati A, Altman DG, Tetzlaff J, Mulrow C, Gøtzsche PC, Ioannidis JP, et al. The PRISMA statement for reporting systematic reviews and meta-analyses of studies that evaluate health care interventions: explanation and elaboration. PLoS Med. 2009;6(7):e1000100.

59. McMaster DT, Gill N, Cronin J, McGuigan M. The development, retention and decay rates of strength and power in elite rugby union, rugby league and American football. Sports Med. 2013;43(5):367-84.

60. Brughelli M, Cronin J, Levin G, Chaouachi A. Understanding change of direction ability in sport. Sports Med. 2008;38(12):1045-63.

61. Haugen TA, Breitschädel F, Samozino P. Power-force-velocity profiling of sprinting athletes: methodological and practical considerations when using timing gates. J Strength Cond Res. 2018.

62. Gurevitch J, Koricheva J, Nakagawa S, Stewart G. Metaanalysis and the science of research synthesis. Nature. 2018;555(7695): 175 .

63. Ades A, Lu G, Higgins J. The interpretation of randomeffects meta-analysis in decision models. Med Decis Mak. 2005;25(6):646-54.

64. Winwood PW, Cronin JB, Posthumus LR, Finlayson SJ, Gill ND, Keogh JW. Strongman vs. traditional resistance training effects on muscular function and performance. J Strength Cond Res. 2015;29(2):429-39.

65. Helgerud J, Rodas G, Kemi O, Hoff J. Strength and endurance in elite football players. Int J Sports Med. 2011;32(9):677.

66. Haugen T, Tønnessen E, Øksenholt Ø, Haugen FL, Paulsen G, Enoksen E, et al. Sprint conditioning of junior soccer players: effects of training intensity and technique supervision. PLoS ONE. 2015;10(3):e0121827.

67. Hopkins W, Marshall S, Batterham A, Hanin J. Progressive statistics for studies in sports medicine and exercise science. Med Sci Sports Exerc. 2009;41(1):3.

68. Higgins J, Thompson SG. Quantifying heterogeneity in a metaanalysis. Stat Med. 2002;21(11):1539-58. 
69. Swann C, Moran A, Piggott D. Defining elite athletes: issues in the study of expert performance in sport psychology. Psychol Sport Exerc. 2015;16:3-14.

70. Sterne JA, Egger M, Moher D. Addressing reporting biases. Cochrane handbook for systematic reviews of interventions: Cochrane book series; 2008. p. 297-333.

71. Coutts A, Reaburn P, Piva TJ, Murphy A. Changes in selected biochemical, muscular strength, power, and endurance measures during deliberate overreaching and tapering in rugby league players. Int J Sports Med. 2007;28(2):116-24.

72. Coutts AJ, Murphy AJ, Dascombe BJ. Effect of direct supervision of a strength coach on measures of muscular strength and power in young rugby league players. J Strength Cond Res. 2004;18(2):316-23.

73. Alves JMVM, Rebelo AN, Abrantes C, Sampaio J. Short-term effects of complex and contrast training in soccer players' vertical jump, sprint, and agility abilities. J Strength Cond Res. 2010;24(4):936-41.

74. Asadi A, Ramirez-Campillo R, Arazi H, Sáez de Villarreal E. The effects of maturation on jumping ability and sprint adaptations to plyometric training in youth soccer players. J Sports Sci. 2018:1-7.

75. Barr MJ, Gabbett TJ, Newton RU, Sheppard JM. Effect of 8 days of a hypergravity condition on the sprinting speed and lower-body power of elite rugby players. J Strength Cond Res. 2015;29(3):722-9.

76. Beato M, Bianchi M, Coratella G, Merlini M, Drust B. Effects of plyometric and directional training on speed and jump performance in elite youth soccer players. J Strength Cond Res. 2018;32(2):289-96.

77. Borges JH, Conceição MS, Vechin FC, Pascoal EHF, Silva RP, Borin JP. The effects of resisted sprint vs. plyometric training on sprint performance and repeated sprint ability during the final weeks of the youth soccer season. Sci Sports. 2016;31(4):e101-5.

78. Bouguezzi R, Chaabene H, Negra Y, Ramirez-Campillo R, Jlalia Z, Mkaouer B, et al. Effects of different plyometric training frequency on measures of athletic performance in prepuberal male soccer players. J Strength Cond Res. 2018.

79. Bremec D. Very heavy resisted sprinting: a better way to improve acceleration? Effects of a 4-week very heavy resisted sprinting intervention on acceleration, sprint and jump performance in youth soccer players [Masters Thesis]: Swedish School of Sport and Health Sciences; 2018.

80. Brito J, Vasconcellos F, Oliveira J, Krustrup P, Rebelo A. Shortterm performance effects of three different low-volume strengthtraining programmes in college male soccer players. J Hum Kinet. 2014;40(1):121-8.

81. Cavaco B, Sousa N, dos Reis VM, Garrido N, Saavedra F, Mendes R, et al. Short-term effects of complex training on agility with the ball, speed, efficiency of crossing and shooting in youth soccer players. J Hum Kinet. 2014;43(1):105-12.

82. Chelly MS, Ghenem MA, Abid K, Hermassi S, Tabka Z, Shephard RJ. Effects of in-season short-term plyometric training program on leg power, jump-and sprint performance of soccer players. J Strength Cond Res. 2010;24(10):2670-6.

83. Christou M, Smilios I, Sotiropoulos K, Volaklis K, Pilianidis T, Tokmakidis SP. Effects of resistance training on the physical capacities of adolescent soccer players. J Strength Cond Res. 2006;20(4):783-91.

84. Comfort P, Haigh A, Matthews MJ. Are changes in maximal squat strength during preseason training reflected in changes in sprint performance in rugby league players? J Strength Cond Res. 2012;26(3):772-6.

85. Coratella G, Beato M, Milanese C, Longo S, Limonta E, Rampichini S, et al. Specific adaptations in performance and muscle architecture after weighted jump-squat vs. body mass squat jump training in recreational soccer players. J Strength Cond Res. 2019;32(4):921-9.

86. de Hoyo M, Pozzo M, Sañudo B, Carrasco L, Gonzalo-Skok $\mathrm{O}$, Domínguez-Cobo S, et al. Effects of a 10-week in-season eccentric-overload training program on muscle-injury prevention and performance in junior elite soccer players. Int J Sports Physiol Perform. 2015;10(1):46-52.

87. de Hoyo M, Gonzalo-Skok O, Sañudo B, Carrascal C, PlazaArmas JR, Camacho-Candil F, et al. Comparative effects of inseason full-back squat, resisted sprint training, and plyometric training on explosive performance in U-19 elite soccer players. J Strength Cond Res. 2016;30(2):368-77.

88. de Villarreal ES, Suarez-Arrones L, Requena B, Haff GG, Ferrete C. Effects of plyometric and sprint training on physical and technical skill performance in adolescent soccer players. J Strength Cond Res. 2015;29(7):1894-903.

89. Derakhti M. Very heavy resisted sprint training for adolescent football players: a training intervention on acceleration, sprint and jump performance in late pubertal adolescent athletes [Masters of sports science]: Swedish School of sport and health science; 2018.

90. Enoksen E, Staxrud M, Tønnessen E, Shalfawi S. The effect of supervised strength training on young elite male soccer players' physical performance. Serbian J Sports Sci. 2013;7(4):173-9.

91. Faude O, Roth R, Di Giovine D, Zahner L, Donath L. Combined strength and power training in high-level amateur football during the competitive season: a randomised-controlled trial. J Sports Sci. 2013;31(13):1460-7.

92. Franco-Marquez F, Rodriguez-Rosell D, Gonzalez-Suarez J, Pareja-Blanco F, Mora-Custodio R, Yanez-Garcia J, et al. Effects of combined resistance training and plyometrics on physical performance in young soccer players. Int J Sports Med. 2015;94(11):906-14.

93. Gabbett TJ, Johns J, Riemann M. Performance changes following training in junior rugby league players. J Strength Res. 2008;22(3):910-7.

94. García-Pinillos F, Martínez-Amat A, Hita-Contreras F, MartínezLópez EJ, Latorre-Román PA. Effects of a contrast training program without external load on vertical jump, kicking speed, sprint, and agility of young soccer players. J Strength Cond Res. 2014;28(9):2452-60.

95. Gil S, Barroso R, do Crivoi CE, Loturco I, Kobal R, Tricoli V, et al. Effects of resisted sprint training on sprinting ability and change of direction speed in professional soccer players. J Sports Sci. 2018;36(17):1923-9.

96. González-Badillo JJ, Pareja-Blanco F, Rodríguez-Rosell D, Abad-Herencia JL, del Ojo-López JJ, Sánchez-Medina L. Effects of velocity-based resistance training on young soccer players of different ages. J Strength Cond Res. 2015;29(5):1329-38.

97. González-García J, Morencos E, Balsalobre-Fernández C, Cuéllar-Rayo Á, Romero-Moraleda B. Effects of 7-week hip thrust versus back squat resistance training on performance in adolescent female soccer players. Sports. 2019;7(4).

98. Gorostiaga E, Izquierdo M, Ruesta M, Iribarren J, GonzalezBadillo J, Ibanez J. Strength training effects on physical performance and serum hormones in young soccer players. Eur J Appl Physiol. 2004;91(5-6):698-707.

99. Griffiths B, Grant J, Langdown L, Gentil P, Fisher J, Steele J. The effect of in-season traditional and explosive resistance training programs on strength, jump height, and speed in recreational soccer players. Res Q Exerc Sport. 2019;90(1):95-102.

100. Hammami M, Gaamouri N, Shephard RJ, Chelly MS. Effects of contrast strength vs. plyometric training on lower limb explosive performance, ability to change direction and neuromuscular adaptation in soccer players. J Strength Cond Res. 2018. 
101. Hammami M, Negra Y, Aouadi R, Shephard RJ, Chelly MS. Effects of an in-season plyometric training program on repeated change of direction and sprint performance in the junior soccer player. J Strength Cond Res. 2016;30(12):3312-20.

102. Hammami R, Granacher URS, Makhlouf I, Behm DG, Chaouachi A. Sequencing effects of balance and plyometric training on physical performance in youth soccer athletes. J Strength Cond Res. 2016;30(12):3278-89.

103. Harries SK, Lubans DR, Buxton A, MacDougall THJ, Callister R. Effects of 12-weeks resistance training on sprint and jump performance in competitive adolescent rugby union players. J Strength Cond Res. 2017.

104. Harris NK, Cronin JB, Hopkins WG, Hansen KT. Squat jump training at maximal power loads vs. heavy loads: effect on sprint ability. J Strength Cond Res. 2008;22(6):1742-9.

105. Harrison AJ, Bourke G. The effect of resisted sprint training on speed and strength performance in male rugby players. J Strength Cond Res. 2009;23(1):275-83.

106. Haugen T, Tonnessen E, Leirstein S, Hem E, Seiler S. Not quite so fast: effect of training at $90 \%$ sprint speed on maximal and repeated-sprint ability in soccer players. J Sports Sci. 2014;32(20):1979-86.

107. Impellizzeri FM, Rampinini E, Castagna C, Martino F, Fiorini $\mathrm{S}$, Wisloff U. Effect of plyometric training on sand versus grass on muscle soreness and jumping and sprinting ability in soccer players. Br J Sports Med. 2007;42(1):42-6.

108. Ishøi L, Hölmich P, Aagaard P, Thorborg K, Bandholm T, Serner A. Effects of the Nordic Hamstring exercise on sprint capacity in male football players: a randomized controlled trial. J Sports Sci. 2017:1-10.

109. Kobal R, Loturco I, Barroso R, Gil S, Cuniyochi R, Ugrinowitsch $\mathrm{C}$, et al. Effects of different combinations of strength, power, and plyometric training on the physical performance of elite young soccer players. J Strength Cond Res. 2017;31(6):1468-76.

110. Kobal R, Pereira LA, Zanetti V, Ramirez-Campillo R, Loturco I. Effects of unloaded vs. loaded plyometrics on speed and power performance of elite young soccer players. Front Physiol. 2017;8:742.

111. Koundourakis NE, Androulakis N, Spyridaki EC, Castanas E, Malliaraki N, Tsatsanis C, et al. Effect of different seasonal strength training protocols on circulating androgen levels and performance parameters in professional soccer players. Hormones. 2014;13(1):104-18.

112. Krommes K, Petersen J, Nielsen MB, Aagaard P, Hölmich P, Thorborg K. Sprint and jump performance in elite male soccer players following a 10-week Nordic Hamstring exercise protocol: a randomised pilot study. BMC Res Notes. 2017;10(1):669.

113. Lago-Fuentes C, Rey E, Padrón-Cabo A, de Rellán-Guerra AS, Fragueiro-Rodríguez A, García-Núñez J. Effects of core strength training using stable and unstable surfaces on physical fitness and functional performance in professional female futsal players. $\mathbf{J}$ Hum Kinet. 2018;65(1):213-24.

114. Lockie RG, Murphy AJ, Schultz AB, Knight TJ, de Jonge XAJ. The effects of different speed training protocols on sprint acceleration kinematics and muscle strength and power in field sport athletes. J Strength Cond Res. 2012;26(6):1539-50.

115. Lockie RG, Murphy AJ, Scott BR, Janse de Jonge XA. Quantifying session ratings of perceived exertion for field-based speed training methods in team sport athletes. J Strength Cond Res. 2012;26(10):2721-8.

116. Lockie RG, Murphy AJ, Callaghan SJ, Jeffriess MD. Effects of sprint and plyometrics training on field sport acceleration technique. J Strength Cond Res. 2014;28(7):1790-801.

117. López-Segovia M, Andrés JMP, González-Badillo JJ. Effect of 4 months of training on aerobic power, strength, and acceleration in two under-19 soccer teams. J Strength Cond Res. 2010;24(10):2705-14.

118. Arcos AL, Yanci J, Mendiguchia J, Salinero JJ, Brughelli M, Castagna C. Short-term training effects of vertically and horizontally oriented exercises on neuromuscular performance in professional soccer players. Int J Sports Physiol Perform. 2014;9(3):480-8.

119. Loturco I, Ugrinowitsch C, Tricoli V, Pivetti B, Roschel H. Different loading schemes in power training during the preseason promote similar performance improvements in Brazilian elite soccer players. J Strength Cond Res. 2013;27(7):1791-7.

120. Loturco I, Pereira LA, Kobal R, Zanetti V, Gil S, Kitamura K, et al. Half-squat or jump squat training under optimum power load conditions to counteract power and speed decrements in Brazilian elite soccer players during the preseason. J Sports Sci. 2015;33(12):1283-92.

121. Loturco I, Pereira LA, Kobal R, Zanetti V, Kitamura K, Abad CCC, et al. Transference effect of vertical and horizontal plyometrics on sprint performance of high-level U-20 soccer players. J Sports Sci. 2015;33(20):2182-91.

122. Loturco I, Nakamura FY, Kobal R, Gil S, Abad CC, Cuniyochi $\mathrm{R}$, et al. Training for power and speed: effects of increasing or decreasing jump squat velocity in elite young soccer players. $\mathbf{J}$ Strength Cond Res. 2015;29(10):2771-9.

123. Loturco I, Pereira LA, Kobal R, Maldonado T, Piazzi AF, Bottino A, et al. Improving sprint performance in soccer: effectiveness of jump squat and olympic push press exercises. PLoS ONE. 2016;11(4):e0153958.

124. Loturco I, Kobal R, Kitamura K, Cal Abad CC, Faust B, Almeida L, et al. Mixed training methods: effects of combining resisted sprints or plyometrics with optimum power loads on sprint and agility performance in professional soccer players. Front Physiol. 2017;8:1034

125. Manolopoulos E, Papadopoulos C, Salonikidis K, Katartzi E, Poluha S. Strength training effects on physical conditioning and instep kick kinematics in young amateur soccer players during preseason. Percept Mot Skills. 2004;99(2):701-10.

126. Manouras N, Papanikolaou Z, Karatrantou K, Kouvarakis P, Gerodimos V. The efficacy of vertical vs. horizontal plyometric training on speed, jumping performance and agility in soccer players. Int J Sports Sci Coach. 2016;11(5):702-9.

127. Mathisen GE, Danielsen KH. Effects of speed exercises on acceleration and agility performance in 13-year-old female soccer players. J Phys Educ Sport. 2014;14(4):471-4.

128. Mathisen GE, Svein AP. The effect of speed training on sprint and agility performance in female youth soccer players. J Phys Educ Sport. 2015;15(3):395-9.

129. McMaster D, Gill N, McGuigan M, Cronin J. Effects of complex strength and ballistic training on maximum strength, sprint ability and force-velocity-power profiles of semi-professional rugby union players. J Aust Strength Cond. 2014;22(1):17-30.

130. McMorrow BJ, Ditroilo M, Egan B. Effect of heavy resisted sled sprint training during the competitive season on sprint and change-of-direction performance in professional soccer players. Int J Sports Physiol Perform. 2019;14(8):1066-73.

131. Mendiguchia J, Martinez-Ruiz E, Morin JB, Samozino P, Edouard P, Alcaraz PE, et al. Effects of hamstring-emphasized neuromuscular training on strength and sprinting mechanics in football players. Scand J Med Sci Sports. 2015;25(6):e621-9.

132. Meylan C, Malatesta D. Effects of in-season plyometric training within soccer practice on explosive actions of young players. J Strength Cond Res. 2009;23(9):2605-13.

133. Michailidis Y, Tabouris A, Metaxas T. Effects of plyometric and directional training on physical fitness parameters in youth soccer players. Int J Sports Physiol Perform. 2019;14(3):392-8. 
134. Morin J-B, Petrakos G, Jiménez-Reyes P, Brown SR, Samozino $\mathrm{P}$, Cross MR. Very-heavy sled training for improving horizontal-force output in soccer players. Int J Sports Physiol Perform. 2017;12(6):840-4.

135. Mujika I, Santisteban J, Castagna C. In-season effect of shortterm sprint and power training programs on elite junior soccer players. J Strength Cond Res. 2009;23(9):2581-7.

136. Nakamura D, Suzuki T, Yasumatsu M, Akimoto T. Moderate running and plyometric training during off-season did not show a significant difference on soccer-related high-intensity performances compared with no-training controls. J Strength Cond Res. 2012;26(12):3392-7.

137. Negra Y, Chaabene H, Hammami M, Hachana Y, Granacher URS. Effects of high-velocity resistance training on athletic performance in prepuberal male soccer athletes. J Strength Cond Res. 2016;30(12):3290-7.

138. Negra Y, Chaabene H, Sammoud S, Prieske O, Moran J, Ramirez-Campillo R, et al. The increased effectiveness of loaded versus unloaded plyometric-jump training in improving muscle power, speed, change-of-direction, and kicking-distance performance in prepubertal male soccer players. Int J Sports Physiol Perform. 2019;1:1-25.

139. Ozbar N. Effects of plyometric training on explosive strength, speed and kicking speed in female soccer players. Anthropologist. 2015;19(2):333-9.

140. Ozbar N, Ates S, Agopyan A. The effect of 8-week plyometric training on leg power, jump and sprint performance in female soccer players. J Strength Cond Res. 2014;28(10):2888-94.

141. Pienaar C, Coetzee B. Changes in selected physical, motor performance and anthropometric components of university-level rugby players after one microcycle of a combined rugby conditioning and plyometric training program. J Strength Cond Res. 2013;27(2):398-415.

142. Ramírez-Campillo R, Andrade DC, Izquierdo M. Effects of plyometric training volume and training surface on explosive strength. J Sports Sci Med. 2013;27(10):2714-22.

143. Ramirez-Campillo R, Andrade DC, Álvarez C, Henríquez-Olguín C, Martínez C, Báez-SanMartín E, et al. The effects of interset rest on adaptation to 7 weeks of explosive training in young soccer players. J Sports Sci Med. 2014;13(2):287.

144. Ramírez-Campillo R, Meylan C, Álvarez C, Henríquez-Olguín C, Martínez C, Cañas-Jamett R, et al. Effects of in-season lowvolume high-intensity plyometric training on explosive actions and endurance of young soccer players. J Strength Cond Res. 2014;28(5):1335-42.

145. Ramírez-Campillo R, Burgos $\mathrm{CH}$, Henríquez-Olguín C, Andrade DC, Martínez C, Álvarez C, et al. Effect of unilateral, bilateral, and combined plyometric training on explosive and endurance performance of young soccer players. J Strength Cond Res. 2015;29(5):1317-28.

146. Ramírez-Campillo R, Gallardo F, Henriquez-Olguín C, Meylan CM, Martínez C, Álvarez C, et al. Effect of vertical, horizontal, and combined plyometric training on explosive, balance, and endurance performance of young soccer players. J Strength Cond Res. 2015;29(7):1784-95.

147. Ramírez-Campillo R, González-Jurado JA, Martínez C, Nakamura FY, Peñailillo L, Meylan CM, et al. Effects of plyometric training and creatine supplementation on maximal-intensity exercise and endurance in female soccer players. J Sci Med Sport. 2016;19(8):682-7.

148. Ramirez-Campillo R, Alvarez C, Gentil P, Moran J, García-Pinillos F, Alonso-Martínez AM, et al. Inter-individual variability in responses to 7 weeks of plyometric jump training in male youth soccer players. Front Physiol. 2018;9:1156.

149. Ramirez-Campillo R, Alvarez C, Gentil P, Loturco I, SanchezSanchez J, Izquierdo M, et al. Sequencing effects of plyometric training applied before or after regular soccer training on measures of physical fitness in young players. J Strength Cond Res. 2018.

150. Ramirez-Campillo R, Alvarez C, García-Pinillos F, SanchezSanchez J, Yanci J, Castillo D, et al. Optimal reactive strength index: is it an accurate variable to optimize plyometric training effects on measures of physical fitness in young soccer players? J Strength Cond Res. 2018;32(4):885-93.

151. Ramirez-Campillo R, García-Pinillos F, García-Ramos A, Yanci J, Gentil P, Chaabene H, et al. Effects of different plyometric training frequencies on components of physical fitness in amateur female soccer players. Front Physiol. 2018;9.

152. Ramirez-Campillo R, Alvarez C, García-Pinillos F, Gentil P, Moran J, Pereira LA, et al. Effects of plyometric training on physical performance of young male soccer players: potential effects of different drop jump heights. Pediatr Exerc Sci. 2019;31(3):306-13.

153. Randell AD, Cronin JB, Keogh JWL, Gill ND, Pedersen MC. Effect of instantaneous performance feedback during 6 weeks of velocity-based resistance training on sport-specific performance tests. J Strength Cond Res. 2011;25(1):87-93.

154. Rey E, PadrÓn-Cabo A, FernÁndez-Penedo D. Effects of sprint training with and without weighted vest on speed and repeated sprint ability in male soccer players. J Strength Cond Res. 2017;31(10):2659-66.

155. Rimmer E, Sleivert G. Effects of a plyometrics intervention program on sprint performance. J Strength Cond Res. 2000;14(3):295-301.

156. Rodríguez-Rosell D, Franco-Márquez F, Pareja-Blanco F, MoraCustodio R, Yáñez-García JM, González-Suárez JM, et al. Effects of 6 weeks resistance training combined with plyometric and speed exercises on physical performance of pre-peakheight-velocity soccer players. Int J Sports Physiol Perform. 2016;11(2):240-6.

157. Rodríguez-Rosell D, Franco-MÁrquez F, Mora-Custodio R, GonzÁlez-Badillo JJ. Effect of high-speed strength training on physical performance in young soccer players of different ages. J Strength Cond Res. 2017;31(9):2498-508.

158. Rodríguez-Rosell D, Torres-Torrelo J, Franco-Márquez F, González-Suárez JM, González-Badillo JJ. Effects of lightload maximal lifting velocity weight training vs. combined weight training and plyometrics on sprint, vertical jump and strength performance in adult soccer players. J Sci Med Sport. 2017;20(7):695-9.

159. Marques DL, Travassos B, Sousa AC, Gil MH, Ribeiro JN, Marques MC. Effects of low-moderate load high-velocity resistance training on physical performance of under-20 futsal players. Sports. 2019;7(3).

160. Ronnestad BR, Kvamme NH, Sunde A, Raastad T. Short-term effects of strength and plyometric training on sprint and jump performance in professional soccer players. J Strength Cond Res. 2008;22(3):773-80

161. Sanchez-Sanchez J, Perez S, Yaguee J, Royo J, Martin J. Implementation of a resistance training on young football players. Int J Med Sci Phys Act Sports. 2015;15(57):45-59.

162. Scott BR, Peiffer JJ, Goods PSR. The effects of supplementary low-load blood flow restriction training on morphological and performance-based adaptations in team sport athletes. J Strength Cond Res. 2017;31(8):2147-54.

163. Shalfawi SA, Ingebrigtsen J, Dillern T, Tønnessen E, Delp TK, Enoksen E. The effect of $40 \mathrm{~m}$ repeated sprint training on physical performance in young elite male soccer players. Serbian J Sports Sci. 2012;6(3).

164. Seitz LB, Barr M, Haff GG. Effects of sprint training with or without ball carry in elite rugby players. Int J Sports Physiol Perform. 2015;10(6):761-6. 
165. Singh A, Kulkarni K, Shenoy S, Sandhu J. Effect of 6 weeks of preseason concurrent muscular strength and plyometric training in professional soccer players. J Postgrad Med Educ Res. 2014;48(1):27-32.

166. Söhnlein Q, Müller E, Stöggl TL. The effect of 16-week plyometric training on explosive actions in early to mid-puberty elite soccer players. J Strength Cond Res. 2014;28(8):2105-14.

167. Styles WJ, Matthews MJ, Comfort P. Effects of strength training on squat and sprint performance in soccer players. J Strength Cond Res. 2016;30(6):1534-9.

168. Suarez-Arrones L, Lara-Lopez P, Rodriguez-Sanchez P, Lazaro-Ramirez JL, Di Salvo V, Guitart M, et al. Dissociation between changes in sprinting performance and Nordic hamstring strength in professional male football players. PLoS ONE. 2019;14(3):e0213375.

169. Thomas K, French D, Hayes PR. The effect of two plyometric training techniques on muscular power and agility in youth soccer players. J Strength Cond Res. 2009;23(1):332-5.

170. Tønnessen E, Shalfawi SA, Haugen T, Enoksen E. The effect of 40-m repeated sprint training on maximum sprinting speed, repeated sprint speed endurance, vertical jump, and aerobic capacity in young elite male soccer players. J Strength Cond Res. 2011;25(9):2364-70.

171. Torres-Torrelo J, Rodríguez-Rosell D, González-Badillo JJ. Light-load maximal lifting velocity full squat training program improves important physical and skill characteristics in futsal players. J Sports Sci. 2017;35(10):967-75.

172. Tous-Fajardo J, Gonzalo-Skok O, Arjol-Serrano JL, Tesch P. Enhancing change-of-direction speed in soccer players by functional inertial eccentric overload and vibration training. Int $\mathbf{J}$ Sports Physiol Perform. 2016;11(1):66-73.

173. Upton DE. The effect of assisted and resisted sprint training on acceleration and velocity in Division IA female soccer athletes. J Strength Cond Res. 2011;25(10):2645-52.

174. Vera-Assaoka T, Ramirez-Campillo R, Alvarez C, Garcia-Pinillos F, Moran J, Gentil P, et al. Effects of maturation on physical fitness adaptations to plyometric drop jump training in male youth soccer players. J Strength Cond Res. 2019.

175. Weakley J, Till K, Sampson J, Banyard H, Leduc C, Wilson K, et al. The effects of augmented feedback on sprint, jump, and strength adaptations in rugby union players following a four week training programme. Int J Sports Physiol Perform. 2019:1-21.

176. West DJ, Cunningham DJ, Bracken RM, Bevan HR, Crewther BT, Cook CJ, et al. Effects of resisted sprint training on acceleration in professional rugby union players. J Strength Cond Res. 2013;27(4):1014-8.

177. Venturelli M, Bishop D, Pettene L. Sprint training in preadolescent soccer players. Int J Sports Physiol Perform. 2008;3(4):558-62.

178. Wong P-1, Chaouachi A, Chamari K, Dellal A, Wisloff U. Effect of preseason concurrent muscular strength and high-intensity interval training in professional soccer players. J Strength Cond Res. 2010;24(3):653-60.

179. Yanci J, Los Arcos A, Camara J, Castillo D, García A, Castagna C. Effects of horizontal plyometric training volume on soccer players' performance. Res Sports Med. 2016;24(4):308-19.

180. Zghal F, Colson SS, Blain G, Behm DG, Granacher U, Chaouachi A. Combined resistance and plyometric training is more effective than plyometric training alone for improving physical fitness of pubertal soccer players. Front Physiol. 2019;10:1026.

181. Nonnato A, Hulton AT, Brownlee TE, Beato M. The effect of a single session of plyometric training per week on fitness parameters in professional female soccer players: a randomized controlled trial. J Strength Cond Res. 2020. (Publish Ahead of Print).
182. Ross A, Gill N, Cronin J, Cross M. The effects of two power training programmes on the sprint speed, mechanical sprint characteristics, and lower body power of rugby sevens players [Doctor of Philosophy (PhD)]. Auckland: Auckland University of Technology; 2015.

183. Comfort P, Bullock N, Pearson SJ. A comparison of maximal squat strength and 5-, 10-, and 20-meter sprint times, in athletes and recreationally trained men. J Strength Cond Res. 2012;26(4):937-40.

184. Los Arcos A, Yanci J, Mendiguchia J, Salinero JJ, Brughelli M, Castagna C. Short-term training effects of vertically and horizontally oriented exercises on neuromuscular performance in professional soccer players. Int J Sports Physiol Perform. 2014;9(3):480-8.

185. Loturco I, Pereira LA, Reis VP, Bishop C, Zanetti V, Alcaraz $\mathrm{PE}$, et al. Power training in elite young soccer players: effects of using loads above or below the optimum power zone. J Sports Sci. 2019:1-7.

186. Bianchi M, Coratella G, Dello IA, Beato M. Comparative effects of single vs. double weekly plyometric training sessions on jump, sprint and change of directions abilities of elite youth football players. J Sports Med Phys Fit. 2019;59(6):910.

187. Corrêa DA, Soares DS, Gonelli PRG, Cesar MdC, Germano MD, Sindorf MAG, et al. Effect of 29 weeks of periodized soccer training on the neuromuscular performance of soccer players under 20 years of age. J Exerc Physiol Online. 2016;19(4):32-41.

188. Sterne JA, Gavaghan D, Egger M. Publication and related bias in meta-analysis: power of statistical tests and prevalence in the literature. J Clin Epidemiol. 2000;53(11):1119-29.

189. Jones TW, Smith A, Macnaughton LS, French DN. Variances in strength and conditioning practice in elite rugby union between the northern and southern hemispheres. J Strength Cond Res. 2017;31(12):3358-71.

190. Ebben WP, Blackard DO. Strength and conditioning practices of National Football League strength and conditioning coaches. J Strength Cond Res. 2001;15(1):48-58.

191. Higgins JP, Thompson SG, Deeks JJ, Altman DG. Measuring inconsistency in meta-analyses. BMJ. 2003;327(7414):557-60.

192. Cross MR, Lahti J, Brown SR, Chedati M, Jimenez-Reyes P, Samozino P, et al. Training at maximal power in resisted sprinting: optimal load determination methodology and pilot results in team sport athletes. PLoS ONE. 2018;13(4):e0195477.

193. Ramírez-Campillo R, Vergara-Pedreros M, Henríquez-Olguín C, Martínez-Salazar C, Alvarez C, Nakamura FY, et al. Effects of plyometric training on maximal-intensity exercise and endurance in male and female soccer players. J Sports Sci. 2016;34(8):687-93.

194. Macadam P, Nuell S, Cronin JB, Nagahara R, Uthoff AM, Graham SP, et al. Kinematic and kinetic differences in block and split-stance standing starts during $30 \mathrm{~m}$ sprint-running. Eur J Sports Sci. 2019;19(8):1024-31.

195. Douglas J, Pearson S, Ross A, McGuigan M. Reactive and eccentric strength contribute to stiffness regulation during maximum velocity sprinting in team sport athletes and highly trained sprinters. J Sports Sci. 2019:1-9.

196. Coutts AJ, Reaburn P, Piva TJ, Rowsell GJ. Monitoring for overreaching in rugby league players. Eur J Appl Physiol. 2007;99(3):313-24.

197. Cuthbert M, Ripley N, McMahon JJ, Evans M, Haff GG, Comfort $P$. The effect of Nordic hamstring exercise intervention volume on eccentric strength and muscle architecture adaptations: a systematic review and meta-analyses. Sports Med. 2019:1-17.

198. Bouguezzi R, Chaabene H, Negra Y, Ramirez-Campillo R, Jlalia $\mathrm{Z}$, Mkaouer B, et al. Effects of different plyometric training frequency on measures of athletic performance in prepuberal male soccer players. J Strength Cond Res. 2020;34(6). 
199. Medicine ACoS. American College of Sports Med position stand. Progression models in resistance training for healthy adults. Med Sci Sports Exerc. 2009;41(3):687.

200. Jimenez-Reyes P, Samozino P, García Ramos A, Cuadrado V, Brughelli M, Morin J-B. Relationship between vertical and horizontal force-velocity-power profiles in various sports and levels of practice. PeerJ. 2018;6:e5937.

201. Haugen T, Seiler S, Sandbakk O, Tønnessen E. The training and development of elite sprint performance: an integration of scientific and best practice literature. Sports Med Open. 2019;5.

202. Sale D, MacDougall D. Specificity in strength training: a review for the coach and athlete. Can J Appl Sport Sci. 1981;6(2):87-92.

203. Haugen TA, Breitschädel F, Seiler S. Sprint mechanical variables in elite athletes: are force-velocity profiles sport specific or individual? Int J Sports Physiol. 2019;14(7):e0215551.

204. Brearley S, Bishop C. Transfer of training: how specific should we be? Strength Cond J. 2019;41(3):97-109.

205. Kanehisa H, Matsuo A, Fukunaga T. Are peak ground reaction forces related to better sprint acceleration performance? Sports Biomech. 2019:1-10.

206. Nagahara R, Takai Y, Kanehisa H, Fukunaga T. Vertical impulse as a determinant of combination of step length and frequency during sprinting. Int J Sports Med. 2018.

207. Weyand PG, Sternlight DB, Bellizzi MJ, Wright S. Faster top running speeds are achieved with greater ground forces not more rapid leg movements. J Appl Physiol. 2000;89(5):1991-9.

208. Weyand PG, Sandell RF, Prime DN, Bundle MW. The biological limits to running speed are imposed from the ground up. J Appl Physiol. 2010;108(4):950-61.

209. Morin J-B, Edouard P, Samozino P. Technical ability of force application as a determinant factor of sprint performance. Med Sci Sport Exerc. 2011;43(9):1680-8.

210. Morin J-B, Slawinski J, Dorel S, Couturier A, Samozino P, Brughelli $\mathrm{M}$, et al. Acceleration capability in elite sprinters and ground impulse: push more, brake less? J Biomech. 2015;48(12):3149-54.

211. Morin J-B, Bourdin M, Edouard P, Peyrot N, Samozino P, Lacour J-R. Mechanical determinants of 100-m sprint running performance. Eur J Appl Physiol. 2012;112(11):3921-30.

212. Hicks D, Schuster J, Samozino P, Morin J-B. Improving mechanical effectiveness during sprint acceleration: practical recommendations and guidelines. Strength Cond J. 2019;1.

213. Rabita G, Dorel S, Slawinski J, Sàez-de-Villarreal E, Couturier A, Samozino P, et al. Sprint mechanics in world-class athletes: a new insight into the limits of human locomotion. Scand J Med Sci Sports. 2015;25(5):583-94.

214. Morin J-B, Gimenez P, Edouard P, Arnal P, Jiménez-Reyes P, Samozino P, et al. Sprint acceleration mechanics: the major role of hamstrings in horizontal force production. Front Physiol. 2015;6:404.

215. Clark K, Weyand P. Sprint running research speeds up: a first look at the mechanics of elite acceleration. Scand J Med Sci Sports. 2015;25(5):581-2.

216. Moir G. Strength and conditioning. A biomechanical approach. Burlington: Jones \& Bartlett Publishers; 2015.

217. Beardsley C. Why are strength gains specific? (And why does this matter?). Strength and Conditioning research; 2017. https ://www.strengthandconditioningresearch.com/perspectives/justget-strong-is-wrong/.

218. Eston R, Reilly T. Kinanthropometry and exercise physiology laboratory manual: tests, procedures and data: volume two: physiology. London: Routledge; 2013. p. 362.

219. Morin J-B, Samozino P. Interpreting power-force-velocity profiles for individualized and specific training. Int J Sports Physiol Perform. 2016;11(2):267-72.
220. Colyer SL, Nagahara R, Salo AI. Kinetic demands of sprinting shift across the acceleration phase: novel analysis of entire force waveforms. Scand J Med Sci Sports. 2018;28(7):1784-92.

221. Schache AG, Brown NA, Pandy MG. Modulation of work and power by the human lower-limb joints with increasing steadystate locomotion speed. J Exp Biol. 2015;218(15):2472-81.

222. Whitehead S, Till K, Weaving D, Jones B. The use of microtechnology to quantify the peak match demands of the football codes: a systematic review. Sports Med. 2018:1-27.

223. Taylor JB, Wright AA, Dischiavi SL, Townsend MA, Marmon AR. Activity demands during multi-directional team sports: a systematic review. Sports Med. 2017;47(12):2533-51.

224. Phibbs PJ, Jones B, Read DB, Roe GA, Darrall-Jones J, Weakley $\mathrm{JJ}$, et al. The appropriateness of training exposures for matchplay preparation in adolescent schoolboy and academy rugby union players. J Sports Sci. 2018;36(6):704-9.

225. Phibbs PJ, Jones B, Roe GA, Read DB, Darrall-Jones J, Weakley $\mathrm{JJ}$, et al. We know they train, but what do they do? Implications for coaches working with adolescent rugby union players. Int $\mathbf{J}$ Sports Sci Coach. 2017;12(2):175-82.

226. Barnes C, Archer D, Hogg B, Bush M, Bradley P. The evolution of physical and technical performance parameters in the English Premier League. Int J Sports Med. 2014;35(13):1095-100.

227. Wellman AD, Coad SC, Goulet GC, McLellan CP. Quantification of competitive game demands of NCAA Division I college football players using global positioning systems. J Strength Cond Res. 2016;30(1):11-9.

228. Hartwig TB, Naughton G, Searl J. Motion analyses of adolescent rugby union players: a comparison of training and game demands. J Strength Cond Res. 2011;25(4):966-72.

229. Jiménez-Reyes P, Cross M, Ross A, Samozino P, Brughelli M, Gill N, et al. Changes in mechanical properties of sprinting during repeated sprint in elite rugby sevens athletes. Eur J Sports Sci. 2019;19(5):585-94.

230. Nagahara R, Morin J-B, Koido M. Impairment of sprint mechanical properties in an actual soccer match: a pilot study. Int J Sports Physiol Perform. 2016;11(7):893-8.

231. de Souza E. Molecular adaptations to concurrent strength and endurance training. 2019. p. 99-123.

232. Hunter JP, Marshall RN, McNair PJ. Relationships between ground reaction force impulse and kinematics of sprint-running acceleration. J Appl Biomech. 2005;21(1):31-43.

233. Wild J, Bezodis NE, Blagrove R, Bezodis I. A biomechanical comparison of accelerative and maximum velocity sprinting: specific strength training considerations. Prof Strength Cond. 2011;21:23-37.

234. Selye H. Stress and the general adaptation syndrome. Br Med J. 1950;1(4667):1383.

235. Billaut F, Bishop D. Muscle fatigue in males and females during multiple-sprint exercise. Sports Med. 2009;39(4):257-78.

236. Perrey S, Racinais S, Saimouaa K, Girard O. Neural and muscular adjustments following repeated running sprints. Eur J Appl Physiol. 2010;109(6):1027-36.

237. Jimenez-Reyes P, Pareja-Blanco F, Cuadrado-Peñafiel V, Morcillo J, Párraga J, González-Badillo J. Mechanical, metabolic and perceptual response during sprint training. Int J Sports Med. 2016;37(10):807-12.

238. Banister E. Modeling elite athletic performance. In: MacDougall J, Wenger H, Green H, editors. Physiological testing of the highperformance athlete. Champaign: Human Kinetics; 1982.

239. Cissik JM. Means and methods of speed training, Part I. Strength Cond J. 2004;26(4):24-9.

240. Schmidt RA, Wrisberg CA. Motor learning and performance: a situation-based learning approach: Hum Kinet. 2008.

241. Kivi DM. A kinematic comparison of the running A and B drills with sprinting. Manitoba: The University of Manitoba; 1997. 
242. West T, Robson S. Running drills-are we reaping the benefits. 5th ed. Mountain View: TAFNEWS Press; 2000. p. 64-7.

243. Jakalski K. Contemporary research and sprinting: reconsidering the conceptual paradigm of running mechanics. Track Field Coach Rev. 2002;75(1):21-2.

244. Cahill M, Cronin JB, Oliver JL, Clark K, Cross MR, Lloyd RS. Sled pushing and pulling to enhance speed capability. Strength Cond J. 2019;41(4):94-104.

245. Seitz LB, Mina MA, Haff GG. A sled push stimulus potentiates subsequent 20-m sprint performance. J Sci Med Sport. 2017;20(8):781-5.

246. Winwood PW, Posthumus LR, Cronin JB, Keogh JWL. The acute potentiating effects of heavy sled pulls on sprint performance. J Strength Cond Res. 2016;30(5):1248-54.

247. Jiménez-Reyes P, Samozino P, Brughelli M, Morin J-B. Effectiveness of an individualized training based on force-velocity profiling during jumping. Front Physiol. 2017;7:677.

248. Hill A, Long C, Lupton $\mathrm{H}$. The effect of fatigue on the relation between work and speed, in contraction of human arm muscles. J Physiol. 1924;58(4-5):334-7.

249. Handsfield G, Knaus K, Fiorentino N, Meyer C, Hart J, Blemker S. Adding muscle where you need it: non-uniform hypertrophy patterns in elite sprinters. Scand J Med Sci Sports. 2017;27(10):1050-60.

250. Miyake Y, Suga T, Otsuka M, Tanaka T, Misaki J, Kudo S, et al. The knee extensor moment arm is associated with performance in male sprinters. Eur J Appl Physiol. 2017;117(3):533-9.

251. Sugisaki N, Kobayashi K, Tsuchie H, Kanehisa H. Associations between individual lower-limb muscle volumes and 100-m sprint time in male sprinters. Int J Sports Physiol Perform. 2018;13(2):214-9.

252. Haugen T, Tønnessen E, Seiler S. 9.58 and 10.49: nearing the Citius End for $100 \mathrm{~m}$ ? Int J Sports Physiol Perform. 2015;10(2):269-72.

253. Bolger R, Lyons M, Harrison AJ, Kenny IC. Coaching sprinting: expert coaches' perception of resistance-based training. Int J Sports Sci Coach. 2016;11(5):746-54.
254. Healy R, Kenny IC, Harrison AJ. Resistance training practices of sprint coaches. J Strength Cond Res. 2019. (Publish Ahead of Print).

255. Whelan N, Kenny IC, Harrison AJ. An insight into track and field coaches' knowledge and use of sprinting drills to improve performance. Int J Sports Sci Coach. 2016;11(2):182-90.

256. Burnie L, Barratt P, Davids K, Stone J, Worsfold P, Wheat J. Coaches' philosophies on the transfer of strength training to elite sports performance. Int J Sports Sci Coach. 2018;13(5):729-36.

257. Kraemer WJ, Ratamess NA, Nindl BC. Recovery responses of testosterone, growth hormone, and IGF-1 after resistance exercise. J Appl Physiol. 2016;122(3):549-58.

258. Coratella G, Beato M, Schena FJ, RiSM. The specificity of the Loughborough Intermittent Shuttle Test for recreational soccer players is independent of their intermittent running ability. Res Sports Med. 2016;24(4):363-74.

259. Markovic G, Mikulic P. Neuro-musculoskeletal and performance adaptations to lower-extremity plyometric training. Sports Med. 2010;40(10):859-95.

260. Zamparo P, Bolomini F, Nardello F, Beato M. Energetics (and kinematics) of short shuttle runs. Eur J Appl Physiol. 2015;115(9):1985-94.

261. McMillan K, Helgerud J, Grant S, Newell J, Wilson J, Macdonald $\mathrm{R}$, et al. Lactate threshold responses to a season of professional British youth soccer. Br J Sports Med. 2005;39(7):432-6.

262. Samozino P, Rabita G, Dorel S, Slawinski J, Peyrot N, Saez de Villarreal E, et al. A simple method for measuring power, force, velocity properties, and mechanical effectiveness in sprint running. Scand J Med Sci Sports. 2016;26(6):648-58.

263. Cross MR, Brughelli M, Samozino P, Brown SR, Morin J-B. Optimal loading for maximising power during sled-resisted sprinting. Int J Sports Physiol Perform. 2017:1-25.

264. Samozino P, Morin J-B, Hintzy F, Belli A. A simple method for measuring force, velocity and power output during squat jump. J Biomech. 2008;41(14):2940-5.

\section{Affiliations}

\section{Ben Nicholson $^{1,2,3} \cdot$ Alex Dinsdale ${ }^{1} \cdot$ Ben Jones ${ }^{1,3,4,5,6} \cdot$ Kevin Till $^{1,3}$}

1 Carnegie Applied Rugby Research (CARR) Centre, Carnegie School of Sport, Leeds Beckett University, Room G08, Cavendish Hall, Headingley Campus, Leeds LS6 3QS, UK

2 Yorkshire Carnegie Rugby Union Club, Leeds, UK

3 Leeds Rhinos Rugby League Club, Leeds, UK

4 England Performance Unit, The Rugby Football League, Leeds, UK
5 School of Science and Technology, University of New England, Armidale, NSW, Australia

6 Division of Exercise Science and Sports Medicine, Department of Human Biology, Faculty of Health Sciences, The University of Cape Town and the Sports Science Institute of South Africa, Cape Town, South Africa 